\title{
Are environmental exposures to selenium, heavy metals, and pesticides risk factors for amyotrophic lateral sclerosis?
}

\author{
Marco Vinceti ${ }^{1, *}$, Ilaria Bottecchi ${ }^{1}$, Anna Fan ${ }^{2}$, \\ Yoram Finkelstein ${ }^{3}$ and Jessica Mandrioli ${ }^{4}$ \\ ${ }^{1}$ CREAGEN - Environmental, Genetic and Nutritional \\ Epidemiology Research Center, Department of Public \\ Health Sciences, University of Modena and Reggio \\ Emilia, Reggio Emilia, Italy \\ ${ }^{2}$ Pesticide and Environmental Toxicology Branch, Office \\ of Environmental Health Hazard Assessment, State of \\ California, Oakland, CA, USA \\ ${ }^{3}$ Neurology and Toxicology Service and Unit, Shaare \\ Zedek Medical Center, Jerusalem, Israel \\ ${ }^{4}$ Department of Neurosciences, University of Modena \\ and Reggio Emilia and Local Health Unit of Modena, \\ Modena, Italy
}

\begin{abstract}
The etiology of sporadic amyotrophic lateral sclerosis (ALS), the most common form of this degenerative disease of the motor neurons, is still unknown, despite extensive investigation of several genetic and environmental potential risk factors. We have reviewed laboratory and epidemiological studies assessing the role of exposure to neurotoxic chemicals (metalloid selenium; heavy metals mercury, cadmium, and lead; pesticides) in ALS etiology by summarizing the results of these investigations and examining their strengths and limitations. Despite limitations in the exposure assessment methodologies typically used in human studies, we found suggestive epidemiological evidence and biologic plausibility for an association between ALS and antecedent overexposure to environmental selenium and pesticides. The relation with mercury, cadmium, and lead appears weaker.
\end{abstract}

Keywords: heavy metals; motor neuron disease; neurotoxins; pesticides.

\section{Introduction}

Amyotrophic lateral sclerosis (ALS) is a rare and extremely severe human neurodegenerative disease characterized by a

*Corresponding author: Marco Vinceti, CREAGEN - Dipartimento di Scienze di Sanità Pubblica, Università di Modena e Reggio Emilia, Padiglione De Sanctis, Via Amendola 2, 42122 Reggio Emilia, Italia

Phone: +39-0522-522427, Fax +39-0522-522074,

E-mail: marco.vinceti@unimore.it

Received October 11, 2011; accepted January 5, 2012 degeneration of upper and lower motor neurons in both motor cortex and spinal cord, leading to progressive paralysis and death due to respiratory failure (unless mechanical ventilation is supplied). The etiology of this most common form of motor neuron disease (MND), nearly 140 years after its description by Charcot, still remains unknown. Both environmental and genetic factors have been involved in the familial and in the more common sporadic form, the incidence of which might be increasing according to recent reports $(1,2)$ and appears to have uneven spatial distribution (3). Environmental risk factors for which some epidemiological and clinical evidence exists include neurotropic viruses, cyanobacterial toxins, magnetic fields, and several chemicals (4-6). In this review, we have summarized and discussed the evidence supporting a role of environmental exposure to chemical substances in ALS etiology, focusing on a metalloid [selenium (Se)], three heavy metals [mercury $(\mathrm{Hg})$, cadmium $(\mathrm{Cd})$, and lead $(\mathrm{Pb})]$, and pesticides.

\section{Selenium}

Se is a trace element commonly found in very low concentrations in the environment and occurs naturally in several organic and inorganic species. The element is of paramount importance in both toxicological and nutritional aspects (7-10). The main source of Se intake in humans is the diet, although sometimes ambient air in occupational settings and in areas characterized by large combustion of coal $(11,12)$ or in drinking water $(10,13)$ can become relevant sources of exposure. The exact role of Se in human health is still not well defined and highly controversial $(10,14)$, despite recent advancements in the understanding of its dichotomous involvement in human health and disease (10, 12, 14-17). ALS is among the human diseases suggested to derive from excess Se exposure on the basis of two epidemiological studies that found an increased risk of ALS associated with residence in a seleniferous area or with consumption of drinking water with unusually high levels of inorganic hexavalent Se. Laboratory investigations have provided supportive evidence of a cause-effect relation $(18,19)$.

Se has long been recognized as a wide-spectrum neurotoxic agent, based on laboratory studies. In the rat, Se compounds (in most cases, in its inorganic tetravalent form, selenite) were observed to enter the central nervous system (CNS) from peripheral blood vessels, showing an enhanced affinity for the spinal cord and the hypothalamus (20). The metalloid can alter dopamine levels in brain, exert hypothermic and nociceptive responses, impair locomotor activity (21), interfere with prostaglandin D synthesis and activity (22), inhibit at very 
low levels $\delta$-aminolevulinate dehydratase in the CNS (23), and affect the latencies and conduction velocity distribution of sciatic nerve fibers (24). Se compounds increase the activity of lactato dehydrogenase and the amount of thiobarbituric acid reactive substances in the rat brain (25), impair glutamate uptake $(26,27)$, and inhibit succinic dehydrogenase, acetylcholine esterase, and $\mathrm{Na} / \mathrm{K}$ ATPase (28). In cultured primary mouse cortical neurons (29), Se levels as low as 8 $\mu \mathrm{g} / \mathrm{L}$ and even less in its inorganic tetravalent form (selenite) induced apoptosis. Selenite was shown to provoke abnormalities in dopamine metabolites, lipids, and thiobarbituric acid-reactive substances in the striatum $(19,30)$ and cardiorespiratory effects, hind-limb paralysis, and death after intravenous administration (31). Se may also be responsible for the accumulation of a Hg-Se complex in CNS areas (32), with a consequent possible release of these toxic elements into the CNS over time. Depending on its concentration and chemical form, Se toxicity in cultured nervous system cells might be additive or antagonistic to $\mathrm{Hg}$ toxicity (33).

Se compounds are able to damage mitochondrial functions and integrity $(34,35)$, a pattern that might be involved in ALS etiopathogenesis (36). Several lines of evidence support the view that mitochondria are affected in the course of motor neuron degeneration and that mitochondrial dysfunction may actively participate in the demise of motor neurons. Mitochondrial abnormalities have been described in ALS patients. In vitro studies using rabbit aorta have shown $\mathrm{Se}$ compounds to damage vascular smooth muscle reactivity by inhibiting both contracting and relaxing properties (37), which might also be related to the amyotrophic process characterizing ALS. Se also inhibits purified human squalene monooxygenase, a key enzyme for cholesterol biosynthesis (38). Inhibition of this enzyme leads to a peripheral demyelinating neuropathy in rats, which occurs secondary to a systemic block in cholesterol synthesis (39).

All the above-mentioned studies demonstrate the potential neurotoxicity of Se in the experimental animal. Nevertheless, the strongest evidence of a biological plausibility for the Se-ALS association emerges from veterinary medicine studies in swine, which showed that Se intoxication (due to inorganic Se compounds in most cases) results in a selective necrosis of the ventral horns of the spinal cord and other CNS regions (40-45). The induction of symmetrical poliomyelomalacia in pigs was enhanced by inorganic Se compared with organic $\mathrm{Se}$, despite the higher Se tissue content after the administration of the organic form (46). The occurrence of polioencephalomyelomalacia has also been experimentally induced in cattle following the administration of inorganic Se as selenite; neurological signs included trembling of skeletal muscles, enhanced by exercise, which led the treated animals to shiver (47), resembling the blind-staggers originally described in livestock from seleniferous areas in the USA (12). Sodium selenite was found to be toxic to chicks, inducing neuromuscular blockade and tetanic spasm: the compound blocked axonal conduction and directly affected the muscle membrane by releasing $\mathrm{Ca}^{2+}$ from the sarcoplasmic reticulum (18). Selenite also inhibited neurotransmitter release and axonal conduction in a mouse phrenic nerve-diaphragm preparation (48).
Morgan et al. (49) have shown the capability of long-term Se exposure to impair locomotor activity and even to paralyze the nematode Caenorhabditis elegans, likely due to a Se-induced generation of reactive oxygen species (ROS).

Overall, in the light of the above studies, Se appears to exert selective toxicity on the motor neurons in several animal species at least. The same pathological feature characterizes ALS and seems to be a distinctive feature of Se compared with all other chemicals, to the best of our knowledge. Such neurotoxic effects of $\mathrm{Se}$, however, may vary considerably according to the animal species and the chemical forms of the metalloid involved $(12,14,50)$.

The key evidence linking Se to ALS, however, is based on epidemiological evidence arising from human studies. The first investigation to suggest a relation between exposure to environmental Se and ALS was a report published in 1977 by a physician in a private practice, Arthur Kilness, and the Harvard neurologist Fred Hochberg, who described the occurrence of a cluster of four cases of ALS among male ranchers within a sparsely populated South Dakota county (around 4000 inhabitants) during an 11-year period (51). The authors also outlined the early veterinary medicine observations that showed the occurrence of the so-called blind-staggers disease in livestock chronically intoxicated with $\mathrm{Se}$, as well as the finding of spinal cord degeneration in malformed embryos of hens characterized by excess Se intake, and remarked on the need to further investigate environmental Se as a potential risk factor for human ALS. This study had some limitations, however, such as the lack of a prespecified area and period of the study and, more importantly, the possibility of ecological bias due to other environmental or genetic factors.

A few case-control studies were subsequently carried out to investigate the role of Se exposure in ALS etiology, although the lack of specific biomarkers of long-term exposure to the metalloid, as well as the severe impairment of health status occurring during early disease progression, substantially hampered the assessment of long-term antecedent exposure in patients. Two studies found higher Se levels in the spinal cord of ALS patients compared with controls $(52,53)$, whereas in two Italian studies, blood and toenail Se concentrations were not increased in such patients $(54,55)$. The results of these studies also suggest that the nutritional status of patients might severely alter the circulating Se levels and, therefore, that case-control studies lacking long-term indicators of exposure are unsuitable to investigate the Se-ALS relation. Furthermore, no studies were conducted on the possible relation between the different Se chemical forms and ALS risk, which further hinders our ability to assess this issue, considering the differences in the biological activity and toxicity of the different Se compounds. Other observations from seleniferous areas of China indicated the potential of environmental Se to induce slight to severe motor disorders in humans (56, 57), although no such effect was recently reported in a population the Brazilian Amazon characterized by high Se intake and which also has the highest $\mathrm{Hg}$ exposures reported in the world today (58). The authors noted that their results are not necessarily applicable to populations with lower $\mathrm{Hg}$ exposure and/or Se status. Signs of neurotoxicity were also detected 
in Inuit children from Northern Quebec exposed to high levels of methyl-Hg, polychlorinated biphenyl, and Se, but in that case, the adverse effects were exerted on visual-evoked potentials (59).

Two studies carried out in a peculiar Italian area, where a limited population experienced intake of inorganic hexavalent $\mathrm{Se}$ (selenate) for several years, have provided new and suggestive evidence linking environmental Se with ALS $(60,61)$. The study area was Rivalta, a neighbor of the city of Reggio Emilia in Northern Italy (around 150,000 inhabitants), where during the 1970s and the 1980s, the public water supply system had to be separated from the remaining system due to technical reasons. The Rivalta aqueduct was connected to two local wells providing, as detected several years later, water with an unusually high content of Se (around $8 \mu \mathrm{g} / \mathrm{L}$ ) in its inorganic hexavalent form, selenate, the species usually found in underground waters (Figure 1) $(62,63)$. Consumption of this high-Se drinking water by the local population (2000 to $>6000$ residents, according to length of drinking water consumption) was unknown to both the population itself and the Municipal Water Authority until 1988 (60, 62, 64). Only then, due to the disclosure of the high Se content, were the two wells disconnected from the municipal aqueduct, and the Rivalta aqueduct shared the water distributed in the remaining municipality, containing $<1 \mu \mathrm{g} \mathrm{Se} / \mathrm{L}$. This situation provided the unusual design of a 'natural experiment', a situation of strong interest in epidemiology to investigate adverse health effects of toxicants that cannot be studied in planned experimental studies for obvious ethical reasons. Indeed, the exposed population was unaware of the high Se content of the drinking water they consumed, and no other chemical features differentiated the tap water distributed in Rivalta from the tap water supplied to the remaining municipality. The subjects consuming the high-Se drinking water in Rivalta and the remaining municipal population also appeared to be considerably similar regarding their socioeconomic characteristics $(62,63)$. This situation provided an optimal setting to perform a cohort study, originally designed under the hypothesis that a higher Se intake in Rivalta might be associated with beneficial effects on cancer and cardiovascular risk $(64,65)$ but later including other adverse effects, such as ALS incidence in the follow-up (60). Long-term consumption of the high-Se drinking water was associated with a strong increase in ALS risk [4.2, 95\% confidence interval (CI) 1.2-10.8], which was even higher when we limited the analysis to the 2065 individuals having the longest exposure $(8.9,95 \% \mathrm{CI}$, 2.4-22.8) (60). Several years after this report, an analysis of the Se-ALS relation was repeated in the same locale, with two key methodological variations to the study design: extension of the analysis to any source and period of consumption of high-Se drinking water and choice of a case-control approach. The ALS incidence was assessed among the exposed subjects in the period 1995-2006, immediately subsequent to that examined in the prior cohort study (1986-1994) (61). The

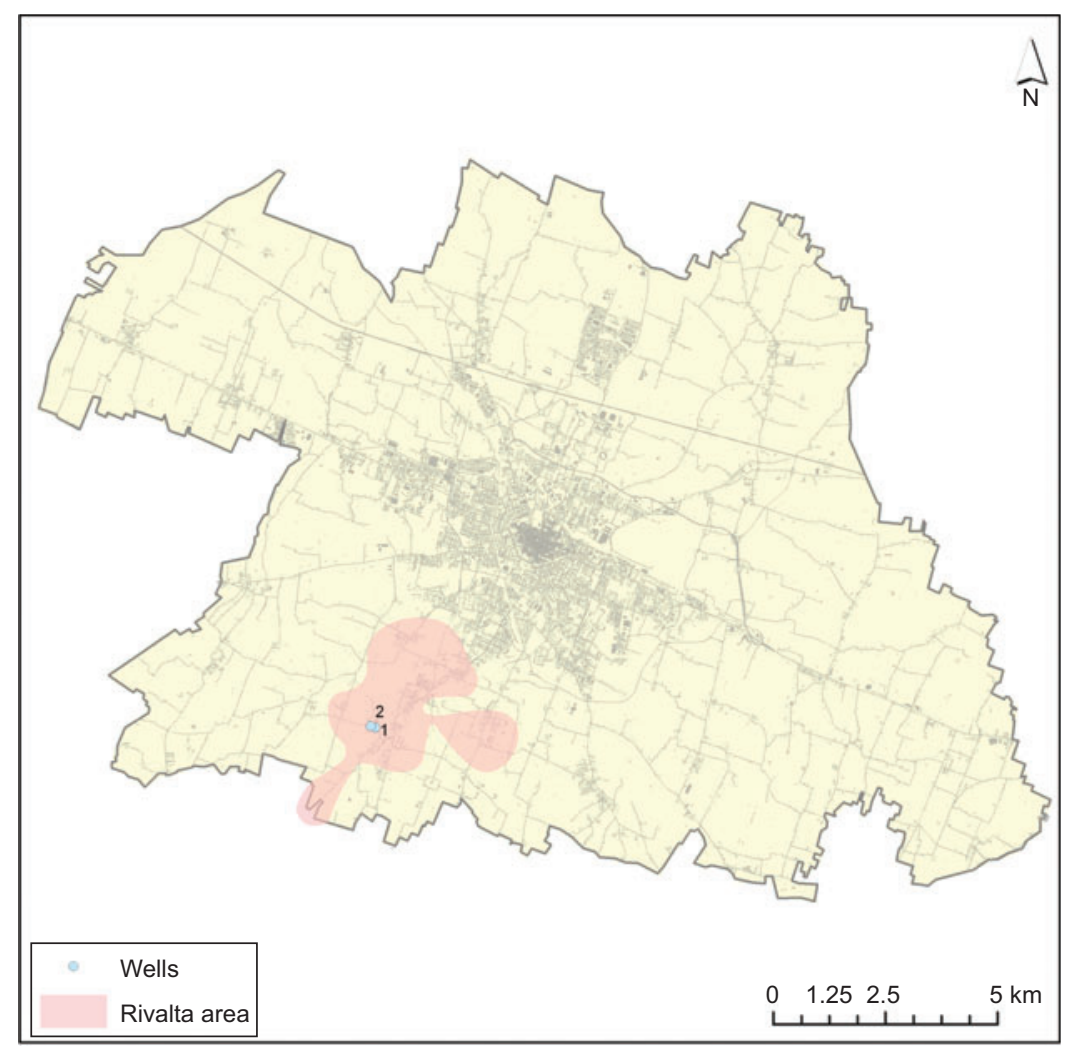

Figure 1 Map of the Rivalta area in the Reggio Emilia municipality (extension, $231.6 \mathrm{~km}^{2}$; population, $\sim 150,000$ ), where tap water with unusually high content of inorganic hexavalent Se from the two local wells, 1 and 2, was distributed from 1972 to 1988. 
results of this investigation confirmed an association between drinking water (inorganic) Se and ALS, showing a relative risk (RR) of 5.4 (95\% CI, 1.1-26) for the consumption of tap water with $\mathrm{Se} \geq 1 \mu \mathrm{g} / \mathrm{L}$ after adjustment for potential confounders and evidence of a dose-response relation between the long-term intake of inorganic Se and disease risk (61). Overall, the results confirmed the likelihood of a selective relation between Se and ALS in the municipal population under study, suggesting that major sources of bias were unlikely to occur.

Thus, the epidemiological evidence suggests that Se may cause or contribute to triggering ALS. As high Se areas are detected in various parts of the world $(7,10,11)$ and occupational exposures to Se compounds may occur, further epidemiological studies for the ascertainment of this issue appear feasible and should be seriously pursued (12). In line with the usual paradoxes characterizing Se research, we should note that due to the antioxidant activity of the Se-containing enzymes glutathione peroxidases, the metalloid has also been considered a potential tool in the therapy of the disease, but a careful analysis of the epidemiological data has not provided convincing evidence of such an effect (66).

\section{Mercury}

The heavy metal $\mathrm{Hg}$ exists in a wide variety of physical states: elemental $\mathrm{Hg}$, organic, and inorganic $\mathrm{Hg}$ compounds. The neurotoxic effects of elemental Hg (e.g., 'mad hatter syndrome') have been known for centuries, and the first detailed account of the clinical neurotoxic syndrome induced by occupational exposure to organic $\mathrm{Hg}$ compounds was published in 1940 (67). A massive epidemic of organic $\mathrm{Hg}$ poisoning became known in the 1950s following the Minamata disease outbreak in Japan $(68,69)$. Subsequent studies have implicated $\mathrm{Hg}$ in the etiology of several neurodegenerative disorders, including Alzheimer disease and ALS (70).

Elemental $\mathrm{Hg}$ is liquid at cool room temperatures and in this form is less toxic than inorganic or organic $\mathrm{Hg}$ compounds. When heated, however, $\mathrm{Hg}$ evaporates and becomes highly toxic. In an aquatic environment, elemental $\mathrm{Hg}$ may also undergo biomethylation by bacteria and algae: the organic compounds that are obtained, such as methyl-Hg and ethyl-Hg, accumulate in fish, crustaceans, and throughout the food chain to humans. These compounds can adversely affect human health because they are rapidly and completely absorbed from the gastrointestinal tract; they can bind to free cysteine, after which the final complex may replace methionine. Because of this mimicry, organic $\mathrm{Hg}$ compounds can be transported freely throughout the body and pass through the blood-brain barrier and the placenta, with consequent harm to the developing fetus (71). Occupational exposure to elemental $\mathrm{Hg}$ has also been associated with parkinsonism (72). In animal studies, inorganic $\mathrm{Hg}$-chloride $\left(\mathrm{HgCl}_{2}\right)$ has been shown to concentrate in the cerebellar gray matter, area postrema, and hypothalamus, whereas organic $\mathrm{Hg}$ compounds have a more uniform distribution (73-76). Hg-chloride, in particular, induces evident nervous tissue atrophy, alongside a reduced number of neurons and with the proliferation of astrocytosis, glial fibers, and capillary networks. The disruption of granule cells in rat cerebellum following dimethylmercuric sulfide administration has been reported (77). In addition to the neuronal body, $\mathrm{Hg}$ may damage myelin sheaths, which lose their laminar structure (78-80).

This heavy metal may damage blood-brain barrier function due to its capacity to form cross-linkages with cell membrane proteins, thus inducing its permeability (81). Steinwall and colleagues (82-84) demonstrated that this process occurs when $\mathrm{Hg}$ is administered at high dosages or is perfused directly into the CNS. Once the blood-brain barrier is disrupted, however, $\mathrm{Hg}$ ions, especially in the organic forms (73), may exert various neurotoxic effects on the adult CNS, affecting different intracellular organelles. In the rat, $\mathrm{Hg}$ intoxication impairs protein synthesis (85-87). $\mathrm{Hg}$ also adversely affects several enzymatic activities, decreasing the activity of sulfhydryl enzymes such Mg-activated ATPase, fructose-diphosphate aldolase, and succinic deydrogenase (85), increasing acid phosphatase activity with a consequent accumulation in the lysosomes (88), impairing the glycolytic pathway, and decreasing ATP levels (89). In rat nerve cells, $\mathrm{HgCl}_{2}$ markedly reduced RNA levels $(79,80)$, probably by two mechanisms: diminished synthesis of RNA and increased RNA degradation, with a consequent altered RNA turnover. $\mathrm{Hg}$ reacts with and depletes free sulfhydryl groups and determines a decline of superoxide-dismutase (SOD) activity leading to oxidative stress, a mechanism implicated in ALS pathophysiology (90). Interestingly, in a mouse ALS model overexpressing the human SOD type 1 [SOD1 or copper $(\mathrm{Cu})$ zinc ( $\mathrm{Zn}$ ) SOD] gene, chronic exposure to methyl-Hg induced an early onset of hind-limb weakness (69).

Because ALS is characterized, among other effects, by the dislocation of a DNA-binding protein (TDP-43) from nucleus to cytoplasm, forming inclusions (91-93) for a lengthy period (94, 95), Pamphlett and Jew (94) exposed mice to different concentrations of inorganic $\mathrm{Hg}$ (the $\mathrm{HgCl}_{2}$ vapor) for a prolonged time. No TDP-43 inclusions in motor neurons were detected, however, and the exposed mice continued to move and run without presenting weakness or other signs resembling ALS. A single dose of $\mathrm{HgCl}_{2}$ was shown to cause $\mathrm{Hg}$ deposition in spinal motor neurons in mice (96). Noteworthy is that in all ALS forms, TDP-43 inclusions are generally found, with the exception of SOD1 mutation-associated disease, suggesting that $\mathrm{Hg}$ might play a role only in the latter (95). Neurophysiologic studies also suggested that $\mathrm{Hg}$ slows conduction velocity in dorsal roots and repolarization $(97,98)$. Also, low concentrations of methyl- $\mathrm{HgCl}_{2}$ caused a stable increase in the threshold for excitation and blockage of action potentials in isolated squid axons without changing their resting membrane potentials, whereas higher concentrations decreased the resting membrane potentials (99). Although these studies were carried out in different experimental systems, the overall results indicate that $\mathrm{Hg}$ intoxication in the CNS disrupts cellular metabolism and degrades several cellular constituents, eventually leading to cell death and clinical disease. Probably, the biochemical mechanisms and the clinical pictures of $\mathrm{Hg}$ toxicity in the human depend 
on several factors, such as individual genetic susceptibility (specific polymorphisms or mutations); the chemical forms of the metal; and the source, length, timing, and amount of exposure during life.

In the epidemiological literature, a few studies have suggested the possibility of an Hg-ALS exposure-effects linkage. A case of an ALS-like syndrome following exposure to organic $\mathrm{Hg}$ was described in a farmer, who presented with a 3-year history of progressive muscle weakness and died 8 months after diagnosis (100). The authors of this study concluded that exposure to $\mathrm{Pb}$ or $\mathrm{Hg}$ or excessive milk ingestion might have been the events leading to disease onset. Barber (101) and Adams (102) reported cases of inorganic $\mathrm{Hg}$ intoxication leading to ALS-like symptoms, with subsequent resolution of the disease after removal from exposure. More recently, Praline et al. (103) reported the case of an 81-year-old woman affected by ALS who presented with a high level of $\mathrm{Hg}$ in the blood, urine, and spinal cord. Despite a therapeutic trial with a chelating agent, the $\mathrm{Hg}$ levels remained elevated, indicating heavy $\mathrm{Hg}$ body burden due to severe antecedent chronic $\mathrm{Hg}$ intoxication. An association between $\mathrm{Hg}$ and ALS was also suggested in the case of a 24-year-old man who injected himself intravenously with elemental $\mathrm{Hg}$ in a suicide attempt; he died 5 months later after heroin injection and wrist laceration but without a clinical history of ALS. Postmortem examination showed, however, dense deposits of $\mathrm{Hg}$ in large cortical motor neurons but not in other neurons, whereas all glial cells were occupied by $\mathrm{Hg}$ deposits.

Two studies did not find an association between $\mathrm{Hg}$ exposure and ALS. In a retrospective case-control study carried out on 66 patients and 66 age- and gender-matched controls, Gresham et al. (104) investigated, through a self-administered questionnaire, exposure to nine heavy metals, including $\mathrm{Hg}$ and Se. Another 'negative' case-control study was that conducted by Moriwaka et al. (105) in subjects living in the non-endemic area of Hokkaido, Japan: Hg concentrations in plasma, blood cells, and scalp hair were lower in 21 ALS patients than in their 36 controls, although such abnormalities were considered by the authors to be a disease-induced effect.

In conclusion, humans exposed to various forms of $\mathrm{Hg}$ may have neurotoxic effects, including in utero and postpartum exposures, but no convincing evidence has emerged for an involvement of this heavy metal in ALS etiology. Too few human studies have, however, been conducted on this issue, and most were affected by methodological limitations concerning exposure assessment and/or confounders control. In addition, the results of epidemiological investigations have been conflicting.

\section{Cadmium}

Pure $\mathrm{Cd}$ is found naturally in small quantities in air, water, and soil. $\mathrm{Cd}$ in the environment occurs as a byproduct of the smelting of other metals, such as $\mathrm{Zn}, \mathrm{Pb}$, and $\mathrm{Cu}$, and its distribution is increased due to human activities. The ingestion of foods, such as cereals, seafood, and offal and the inhalation of tobacco smoke are generally considered the main sources of environmental Cd exposure (106). Occupational exposure is frequently due to fume inhalation, working in the nickel (Ni)-Cd battery industry, and exposure to paint pigments. Once absorbed from the gastrointestinal tract, $\mathrm{Cd}$ has a long half-life in the body, as it is not biodegradable.

$\mathrm{Cd}$ stimulates the formation of metallothioneins (MT), a family of cysteine-rich low-molecular-weight metal-binding proteins. Experimental data support the participation of MT in the detoxification of toxic metals, such as $\mathrm{Cd}$ and in scavenging ROS. Cd is red-ox inert as compared with other transitional metals, except when conjugated with MT. The Cd-MT complex is formed in the liver, released into the blood, and transported to the kidneys $(107,108)$. Acute $\mathrm{Cd}$ poisoning causes pulmonary edema and hemorrhage; chronic exposure adversely affects kidney and bone (109). Cd also acts as an endocrine disruptor $(110,111)$ and may thus affect reproduction and child development (112). In addition, $\mathrm{Cd}$ and its compounds are classified by the International Agency for Research on Cancer as a group 1 human carcinogen based on evidence that lung cancer is increased in Cd workers (113). $\mathrm{Cd}$ exposure has also been linked to human prostate and renal cancer, although this linkage is weaker than for lung cancer (114). The role of the metal in liver, pancreas, and stomach carcinogenesis is considered equivocal (115).

Some of the toxicological effects of Cd mirror the biochemical mechanisms underlying ALS pathophysiology, thus providing biological plausibility to a Cd-ALS relation. In particular, considering that $20 \%$ of familial ALS cases show SOD1 gene mutations (5), the capacity of $\mathrm{Cd}$ to alter SOD1 activity is of considerable interest. $\mathrm{Cd}$ can induce MT expression (116), which may act as a protective factor against ROS, but this protein also binds $\mathrm{Zn}$ ions in mammalian cells in addition to $\mathrm{Cd}$ (117), irreversibly decreasing SOD1 enzyme activity (118). Moreover, Cd can interfere with the secondary structure of the SOD1 protein by decreasing its $\mathrm{Zn}$ content and thus enzymatic activity (109) and by inducing misfolding and aggregation of the SOD1 protein (119). These effects were analyzed by spectroscopy, which showed that Cd modifies SOD1 conformation by increasing the $\alpha$-helix structure and decreasing the random coil domain. $\mathrm{Cd}$ also induces SOD1 cytoplasmic inclusions in the proximal axon and neuron cell body, which represent the pathological findings detected in motor neurons and astrocytes from ALS patients (120). Degeneration of the neural tube in Cd-treated embryos of zebra fish has also been demonstrated (121). In particular, if the animal embryos are exposed to Cd before neurulation, a gap in the anterior neural tube is observed, and if exposure follows the closure of the neural tube, upper limb defects may occur $(122,123)$. Other studies confirmed that $\mathrm{Cd}$ induces cell apoptosis, especially in mouse N2A neuroblastoma cells. (109). The mechanism through which $\mathrm{Cd}$ induces programmed cell death is not clear, but proteomic studies identified differences of protein expression and aggregation between control and Cd-treated N2A cells, involving structural proteins, stress-related and chaperone proteins, ROS enzymes, apoptosis, and survival signals (109). 
In the epidemiological literature, of interest is the observation by Pamphlett et al. (124) of higher blood Cd concentrations in 20 ALS patients compared with controls. Successive studies measuring heavy metal levels in ALS patients have produced contradictory results, but in most investigations, Cd appeared to be increased. Bar-Sela et al. (125) reported in 2001 a case of a 44-year-old patient who died from ALS after 9 years of $\mathrm{Cd}$ exposure while working in a Ni-Cd battery plant in Israel. The work conditions and exposures in that plant were extremely hazardous, and the exposure of this patient was considerably more intense than that characterizing his coworkers. In particular, the patient had to shake the barrels to loosen up chunks of $\mathrm{Cd}$, a process releasing $\mathrm{Cd}$-containing fumes. As soon as ALS was diagnosed, the blood Cd level was $8 \mu \mathrm{g} / \mathrm{L}, 10$-fold higher than in non-smoking Israelis, but this concentration might not reflect the long-term antecedent exposure because blood Cd levels are known to fall rapidly when exposure ends (126). The urinary Cd level, an indicator of cumulative past exposure, was $13 \mu \mathrm{g} / \mathrm{L}$ (125). The epidemiological data are extremely limited, but the available evidence suggests that occupations and workplace Cd exposure may be linked with excess ALS risk, but there could have been a contributory role for solvent. The patient was one of many with neurotoxic type syndromes, and many other effects associated with mixed exposures to $\mathrm{Cd}, \mathrm{Ni}$, and solvents in appalling working conditions (127). A case-control study carried out in New England between 1993 and 1996 showed a higher risk of ALS for construction workers [odds ratio $(\mathrm{OR})=2.9 ; 95 \%$ $\mathrm{CI}, 1.2-7.2]$ and precision metal workers $(\mathrm{OR}=3.5 ; 95 \% \mathrm{CI}$, 1.2-10.5), but establishing what compounds - including $\mathrm{Cd}-$ were specifically involved was impossible (128). In accordance, other research gave support to the hypothesis that ALS patients are more likely to have been exposed to heavy metals compared with controls (129-131).

On the other hand, Pierce-Ruhland and Patten (132) were unable to detect long-term excessive exposure to Cd in ALS patients, although overall exposure to heavy metals, such as $\mathrm{Pb}$ and $\mathrm{Hg}$ appeared to be related to disease risk. Their study encompassed 80 MND patients and 78 controls using telephonic interviews. In another case-control study from Australia, no correlation between ALS and antecedent occupational exposure to $\mathrm{Cd}$ or other metals (as ascertained through questionnaires) was found when analyzing 179 disease cases and a corresponding number of controls (133). Interestingly, in an older study based on autopsy samples carried out on 24 patients with ALS and 18 controls, an elevated level of MT in liver and kidneys of patients was detected (134), which may be of considerable interest for ALS etiology, considering the interrelation between MT and Cd.

In summary $\mathrm{Cd}$, a recognized neurotoxic element, is assumed to be involved in ALS etiology on the basis of specific biological plausibility supporting this view, but epidemiological evidence is still lacking due to the very few number of studies (generally with low statistical power) carried out to date. Additionally, despite various international guidelines from the 1990s that have banned the use of $\mathrm{Cd}$ in plastic, PVC, batteries, and electronics and have led to a decrease in $\mathrm{Cd}$ occupational exposure, little evidence has emerged of decreased ALS incidence [which, on the converse, might be increasing (2)]. Thus, although Cd might be involved in ALS etiopathogenesis, such a relation is still far from being demonstrated and we need more reliable data to assess it.

\section{Lead}

$\mathrm{Pb}$ is a naturally occurring metal that is present in small amounts in the earth's crust. In the environment, $\mathrm{Pb}$ derives mainly from human activities, including burning fossil fuels, mining, and manufacturing. $\mathrm{Pb}$ is used in the production of batteries, ammunition, metal products (solder and pipes), and devices to shield $\mathrm{X}$-rays. Due to health concerns, $\mathrm{Pb}$ from gasoline, paints and ceramic products, caulking, and pipe solder has been reduced in recent years; hence, cases of overt $\mathrm{Pb}$ poisoning have become less frequent (135). The toxic effects of $\mathrm{Pb}$ on the nervous system are well known and include $\mathrm{Pb}$ encephalopathy (primarily in children) and a peripheral motor neuropathy (primarily in adults) (136). After absorption from the gut, $\mathrm{Pb}$ is deposited in the soft tissues (liver, kidney, erythrocytes), and then transferred to the bones, where it is stored in a biologically inactive form. Bone $\mathrm{Pb}$ levels increase with age (135). The half-life of $\mathrm{Pb}$ is 1 month in blood, 3-5 years in trabecular bones, such as patella, and 15-25 years in cortical bones, such as tibia. Hence, blood $\mathrm{Pb}$ is generally considered to reflect acute exposure, whereas bone $\mathrm{Pb}$ is believed to reflect cumulative exposure. Prolonged exposure results in increased bone $\mathrm{Pb}$ concentration that persists after the termination of the original exposure (137).

With regard to ALS, the mechanisms underlying $\mathrm{Pb}$ neurotoxicity make the relation of $\mathrm{Pb}$ to ALS biologically plausible because $\mathrm{Pb}$ neurotoxicity depends on the same mechanisms suggested for the pathogenesis of this disease. The pathophysiological mechanisms underlying the development of ALS appear to be multifactorial, with emerging evidence of a complex interaction between genetic and environmental factors. In the last years, in addition to the SOD1 gene, new genes have been discovered (TDP43, FUS, VCP, etc.) that can act synergistically with environmental factors through different pathogenetic mechanisms. Such mechanisms include glutamate neurotoxicity, oxidative stress, mitochondrial or axonal transport dysfunction, autophagy, and protein misfolding. An excessive activation of these postsynaptic receptors by glutamate, known as glutamate-induced excitotoxicity, can incite neurodegeneration through the activation of calciumdependent enzymatic pathways. Glutamate-induced excitotoxicity can also result in the generation of free radicals, which in turn can cause neurodegeneration by damaging intracellular organelles and up-regulating proinflammatory mediators (138). Oxidative stress might also be caused by the toxic gain of function of the SOD1 enzyme following SOD1 mutation (139). In addition, structural abnormalities of mitochondria, dysfunction of the sodium/potassium ion pump, autophagy, and disrupted axonal transport systems have all been implicated in ALS pathogenesis (138). Non-neuronal cells, such as astrocytes and microglia, might also directly contribute to neurodegeneration through mechanisms including insufficient 
release of neurotrophic factors, secretion of neurotoxic mediators, and modulation of glutamate receptor expression (known as noncell autonomous neurodegeneration) (140). Another possible pathogenetic mechanism involves protein misfolding. SOD1 mutations induce conformational instability and misfolding of the SOD1 peptide, resulting in the formation of intracellular aggregates that inhibit normal proteosomic function, disrupting axonal transport systems and vital cellular functions. The TAR DNA binding protein 43 (TDP-43) has also been recognized as a major component of ubiquitinated cytoplasmic protein aggregates in almost all patients with sporadic ALS (sALS) (141). Aggregates of another protein, the fused-in sarcoma protein (FUS), were found in ALS but not in patients with pathological changes in TDP-43 or SOD1, indicating a novel disease pathway (142). Pb can also substitute for calcium in many intracellular reactions, damage mitochondria, and amplify glutamate excitotoxicity (143). Animal studies have suggested that ALS onset may be related to motor neuron function, whereas progression is regulated by neuroglia (144).

Surprisingly, $\mathrm{Pb}$ might injure motor neurons and at the same time stimulate glial cells to provide trophic support to neurons and therefore delay cell death. Experimental evidence supports the view that astrocytes can sequester and buffer $\mathrm{Pb}$ in the CNS, preventing further diffusion of the metal to the neuronal compartment and subsequent neurotoxicity or altered synaptic transmission $(145,146)$. In particular, astrocytes are the cells that preferentially induce cytoprotective and antioxidant gene expression in response to $\mathrm{Pb}$ (147). When pretreated with low, non-toxic $\mathrm{Pb}$ concentrations, astrocytes can induce neuroprotective mechanisms, such as the up-regulation of VEGF (vascular endothelial growth factor) gene expression, and can down-regulate neuroinflammation, as shown by a dramatic reduction of GFAPimmunoreactive astrocytes (148). Accordingly, Barbeito and colleagues (149) found that $\mathrm{Pb}$ exposure prolonged survival in SOD1 transgenic mice.

Hence, $\mathrm{Pb}$ exposure could potentially have opposing actions during the course of ALS, initially promoting the degeneration of motor neurons but later abrogating damage and neuroinflammation mediated by dysfunctional glia (148). Additionally, $\mathrm{Pb}$ decreases $\mathrm{SOD}$ activity in $\mathrm{Pb}$-exposed rats (150) and stimulates antioxidant enzyme hemoxygenase 1 expression in astrocytes (147), mechanisms that could contribute to neuronal protection. Alternatively, another possibility is that factors associated with better survival are also associated with higher $\mathrm{Pb}$ levels in the population, such as gender (men have higher Pb levels and longer ALS survival) but not age because older individuals have higher $\mathrm{Pb}$ levels but shorter ALS survival (151). Another possibility is that $\mathrm{Pb}$ exposure is related not to ALS risk but rather to longer survival, favoring the higher participation of $\mathrm{Pb}$-exposed cases in epidemiological studies, thus being a source of selection bias (151). Another possibility is that of reverse causality, i.e., $\mathrm{Pb}$ levels are a result of ALS due to the decline in physical activity in ALS patients, leading to bone demineralization and the release of $\mathrm{Pb}$ from bone into blood, as also suggested by the direct correlation between blood $\mathrm{Pb}$ and disability due to the disease in a case-control study (54). Nevertheless, the associations of blood and bone $\mathrm{Pb}$ in ALS patients were not appreciably changed by adjusting for physical activity levels $(143,152,153)$ or by bone turnover (152).

In epidemiological studies, $\mathrm{Pb}$ exposure has long been investigated as a potential ALS risk factor and as a factor affecting survival in this disease (154). In the first report on progressive muscular atrophy by Aran (155) in 1850, 3 of 11 cases had contact with $\mathrm{Pb}$, and in 2 cases, $\mathrm{Pb}$ poisoning was diagnosed. A number of cases with lower motor neuron signs and pyramidal involvement can be dated at the first years of the 20th century. More recently, Oh et al. (156) reported a case of ALS in a worker who was exposed to $\mathrm{Pb}$ while working in electronic parts manufacturing. Besides single case reports, a number of case-control studies and registry-based case-control or cohort studies have dealt with this topic. The majority of the case-control studies $(104,131,132,143,152$, 154, 157-159) found some evidence for an association of ALS with $\mathrm{Pb}$ exposure as estimated through the administration of questionnaires. In 1970, Campbell et al. (154), through a case-control study on 74 patients with MND and 74 ageand gender-matched controls, found a history of extensive $\mathrm{Pb}$ exposure in $15 \%$ of patients and in $5.4 \%$ of the controls and a history of bone disease or fracture in $25 \%$ of patients and in $9.4 \%$ of the controls. The authors also found a $54 \%$-year survival rate in MND patients previously exposed to $\mathrm{Pb}$ vs. $16 \%$ in patients without antecedent $\mathrm{Pb}$ exposure. Increased $\mathrm{Pb}$ exposure and increased frequency of bone fractures could suggest a role of toxic $\mathrm{Pb}$ reservoir for the bone, which may release $\mathrm{Pb}$ after traumatic events, thus contributing to ALS onset. Yet, the authors did not find different bone $\mathrm{Pb}$ levels in the two groups. Felmus et al. (157) studied the antecedent events of $\mathrm{Pb}$ exposure in 25 patients with ALS and 50 controls, detecting a higher exposure to $\mathrm{Pb}, \mathrm{Hg}$, athletics, and consumption of milk in patients compared with controls (157). This study was replicated in 1981 with confirmation of the results (132). Armon et al. (158) found that men with ALS had worked more frequently at welding and soldering, suggesting an association between ALS in men and exposure to $\mathrm{Pb}$ vapors. In a study from the Scottish MND Register carried out on 103 ALS patients and their matched controls, history of fractures $(\mathrm{OR}=1.3)$, manual occupation $(\mathrm{OR}=2.6)$, and exposure to $\mathrm{Pb}(\mathrm{OR}=5.7)$, and solvents/chemicals $(\mathrm{OR}=3.3)$ was more frequent in patients (131). Other studies, however, did not confirm these results $(104,160,161)$. Nevertheless, the validity of the early data is still debated. These studies include occupational exposures that epidemiologists often use as a surrogate to assess potentially toxic exposures, and many studies relied on self-reporting through questionnaire use, an approach at risk of recall bias. Indeed, McGuire et al. (159) reported that $\mathrm{Pb}$ exposure based on expert evaluation of self-reported occupational histories by a panel of industrial hygienists was not associated with ALS (OR=1.1), suggesting that recall bias might explain findings obtained on the basis of self-reported data. In another study (143), occupational $\mathrm{Pb}$ exposure based on review of self-reported occupational history was associated with ALS, and the RR was similar to that computed for self-reported $\mathrm{Pb}$ exposure. More 
recently, blood $\mathrm{Pb}$ levels were found to be increased among US veterans affected by ALS compared with controls (152), suggesting that $\mathrm{Pb}$ exposure might at least in part explain the higher risk of ALS noted for military personnel, who can be exposed to $\mathrm{Pb}$ from firing and other practices. Residential and recreational $\mathrm{Pb}$ exposure might also represent a risk factor for ALS, but such exposures are generally lower than those experienced in occupational settings and therefore more difficult to investigate due to a high risk of misclassification. In the Italian province of Modena, ALS rates were higher in residents in the 'ceramic district', where several paving-tile factories were located and induced a severe environmental $\mathrm{Pb}$ pollution than in the unexposed population (162). However, this excess incidence was not confirmed in following studies carried out in the same province (163) or in the neighboring province of Reggio Emilia (164), although the possibility of delayed effects of such extensive $\mathrm{Pb}$ contamination cannot yet be ruled out.

Several studies examined the $\mathrm{Pb}$-ALS relation through an analysis of biomarkers of exposure, but their results were inconsistent. Studies from one group reported that, compared with controls, ALS cases had higher Pb levels in plasma (165), cerebrospinal fluid (166), and muscle (165). Kurlander and Patten (167) reported that even after chelation therapy, postmortem concentration of tissue metals was consistently increased. Other studies yielded null results (168-172), including the population-based investigation by Bergomi et al. (55) on toenails trace elements concentrations in 22 ALS patients and 44 matched controls. In this study, no evidence of an association between ALS risk and toenails trace elements (including $\mathrm{Pb}$ ) was detected.

All the above-mentioned studies have limitations, including small size, possible confounding by uncontrolled factors affecting $\mathrm{Pb}$ levels, and potential bias introduced by the use of hospital-referred controls in some cases. Several factors related to blood and bone $\mathrm{Pb}$ levels, including age, gender, cigarette smoking, alcohol use, and education, are known to be potential confounders in the Pb-ALS relation. A recent study, however, combined biological measures and interviews to analyze this issue (143). The authors studied 109 cases and 256 controls and found that ALS risk was associated to self-reported occupational $\mathrm{Pb}$ exposure $(\mathrm{OR}=1.95)$ and also with increased blood and bone $\mathrm{Pb}$ levels, with $\mathrm{OR}=1.9$ for each $\mu \mathrm{g} / \mathrm{dL}$ increase in $\mathrm{Pb}$ blood levels, $\mathrm{OR}=3.6$ for each unit increase in log-transformed patella $\mathrm{Pb}$, and $\mathrm{OR}=2.3$ for each unit increase in log-transformed patella $\mathrm{Pb}$. The same group also found that $\mathrm{Pb}$ exposure was associated with longer survival in ALS cases (151), an observation apparently contrasting with the previous observation of an excess disease risk in $\mathrm{Pb}$-exposed subjects (143). The same conflicting results had been previously reported by Campbell et al. (154) in the 1970s, which may indicate that $\mathrm{Pb}$ exposure might have different effects on ALS onset and progression.

In conclusion, the data on $\mathrm{Pb}$ as a possible risk factor for ALS are conflicting and inconsistent, and methodological limitations of the epidemiological studies hamper reaching definitive conclusions about this issue. Nevertheless, the possibility that $\mathrm{Pb}$ exposure increases ALS survival deserves further evaluation.

\section{Pesticides}

The four major classes of pesticides include insecticides, herbicides, fungicides, and rodenticides, based on target species, plus other pesticides included in narrower classifications. In the human, exposure to pesticides can occur through the oral, dermal, or inhalation route. Although some pesticides are neurotoxic, these are not generally classified as such. Among pesticides, the organophosphates (OPs, as insecticides) have been associated with ALS following the report of increased incidence of ALS in Persian Gulf War veterans, but no conclusive epidemiological evidence supports this apparent increased risk (69). Returning 1991-1992 veterans were reported to have received prophylactic treatment containing cholinergic inhibitors to protect them against nerve gas and insect pests, and plausibly, such pretreatment could have exacerbated an underlying genetic polymorphism or unmasked other factors that increase the risk of motor neuron effects. The OPs have wide agricultural and home uses.

The primary toxicity of OPs is associated with the acute inhibition of acetyl cholinesterase, the enzyme responsible for the destruction and termination of the biological activity of the neurotransmitter acetylcholine (173-175). A second distinct manifestation of OP poisoning is a paralytic condition called the intermediate syndrome, which consists of a sequence of neurological signs appearing about 24-96 h after the acute cholinergic crisis but before the onset of delayed neuropathy. The major effects are muscle weakness, primarily affecting muscles innervated by the cranial nerves (neck flexors, muscle of respiration) as well as those of the limbs. Cranial nerve palsies are common, respiratory depression and distress are not responsive to atropine or oximes, and death may occur. A third syndrome is the OP-induced delayed neurotoxicity (or OP-induced delayed polyneuropathy), in which the agent binds with neurotoxic esterase without effects on ChE (176).

Other clinical signs and symptoms from impairment of $\mathrm{ChE}$ in muscarinic, nicotinic, and central sites are headache, dizziness, paralysis, ataxia, bradycardia, miosis, weakness, anxiety, excessive sweating, fasciculations, vomiting, diarrhea, abdominal cramps, dyspnea, salivation, tearing, pulmonary edema, and confusion.

No studies have been designed to specifically investigate the potential association of OPs with ALS. Morahan et al. (177) analyzed the potential of pesticides, heavy metals, and chemicals to cause sALS and showed that an impaired capacity of patients to detoxify these toxicants could be related to differences in the MT family of genes, metal transcription factor 1 and glutathione synthetase.

Other studies examined paraoxonase $(\mathrm{PON})$ genes in the investigation of the potential association as described by Johnson and Atchison (69). PON is an A-esterase based on its ability to detoxify the prototype OPs, paraoxon. PON1 detoxifies OPs and has several variants, i.e., PON1, PON2, 
and PON3. PON hydrolyses OPs, and its ability to detoxify them is largely determined by different variants of PON1 as opposed to other variants. Genetic variations have been found in the coding and promoter region of the human PON1 locus that determines the catalytic activity and enzyme levels. Therefore, theoretically, the risk of developing ALS in an individual could increase if the mutation of the PON1 gene increases and if the body concentration of PON1 is suboptimal. Thus, mutations that impair the ability of PON1 to detoxify OPs could increase sensitivity to the toxicity of these pesticides and possibly of $\mathrm{Pb}$, favoring ALS development, as well as the other effects specifically associated with anticholinesterases. No consistency has emerged, however, in establishing a causal link between OPs exposure and mutations in the PON1 gene, based on epidemiological and animal studies. Wills et al. (178) showed that the polymorphism of PON1 genes did not reduce enzyme activity, suggesting that this gene product is unlikely to be involved in ALS etiology. Other studies suggest that among veterans with Gulf War syndrome, US veterans have significantly lower serum concentrations of one form of PON1 allozyme, whereas British veterans have lower concentrations of both allozymes $(\mathrm{Q}$ and $\mathrm{R}$ allozymes), when compared with healthy Gulf War veterans (178). A report of two cases has shown massive increases in CPK - a measure of the breakdown of muscle tissue - in persons with occupational exposure to highly toxic anticholinesterases (179). The authors' suggestion that medical programs for Gulf War veterans with Gulf War syndrome should include surveillance for elevated CPK, abnormalities of neuromuscular conduction, and genetic susceptibility to guide diagnosis and care may also be of value in helping to sort out the possibility of mixed causes.

A case of a slowly progressive MND following chronic exposure to pyrethroids that was indistinguishable from ALS was reported in a 44-year-old woman who, as a food shop proprietor, had been using cans of pyrethroid insecticides containing imiprothrin, phenotorin, D-T80-resmethrin, and D-T80-phthalthrin almost every day for 3 years in an unventilated room (180). Further description follows:

Initially, she experienced tongue numbness, nausea, and rhinitis while using the insecticides. Two years after beginning to use the insecticides, she noticed difficulty lifting heavy objects with her left arm, and her symptoms steadily worsened over the next 8 months. Three months before admission, she developed slurred speech, gait disturbance, and generalized muscle weakness. On admission, neurological examination revealed dysarthria, nasal voice, and dysphagia with fasciculating atrophied tongue, moderate muscle weakness with fasciculation in both upper limbs, predominantly on the left side, and fasciculation in the trunk and both lower limbs. Jaw jerk was hyperactive, and hyperreflexia was seen in all limbs without pathological reflexes. Sensory and autonomic systems were all normal. The patient showed upper and lower motor neuron signs in bulbar, cervical, and lumbosacral regions, consistent with signs in bulbar, cervical, and lumbosacral regions, suggesting clinically definite ALS based on El Escorial criteria. Neurophysiologic studies also indicated both upper and lower motor neuron involvement. Her illness was thought to be caused by pyrethroids for two reasons: [1] the usual manifestations of pyrethroid intoxication, such as tongue numbness, nausea, and rhinitis, preceded the motor dysfunction; [2] the motor symptoms and ongoing denervation potentials partially improved after the cessation of pesticide usage. The case indicates that chronic pyrethroid intoxication may cause an ALS-like disorder in humans, similar to $\mathrm{Pb}$ and domoic acid intoxications. Pyrethroids are synthesized from chrysanthemum extracts, and they disturb ion channels, such as voltage-dependent sodium channels and voltage-sensitive chloride channels, and readily induce neuronal excitation by current prolongation. Moreover, deltamethrin, one of the pyrethroids, is reported to impair axonal transport and then degenerate axons in rats, with impaired axonal flow causing motor neuron death in various animal models of MND. Although pyrethroids have low toxicity, due in part to their rapid detoxification via ester hydrolysis in mammals, some human populations are thought to be poor metabolizers of pyrethroids, whereas carboxyesterase inhibitors can enhance pyrethroid toxicity. Therefore, chronic exposure to pyrethroids may cause MND through disturbance of either ion channels or axonal flow, especially in poor metabolizers (180).

A case simulating MND closely associated with overexposure to a pyrethrin and chlordane-based insecticide has also been reported $(181,182)$. For pyrethrins, such as pymethrin, the elimination of metabolites $4{ }^{\prime}$-hydroxy-3-phenoxy benzyl alcohol or 4'-hydroxy-3-phenoxy benzoic acid occurs by sulfate conjugation, which is the major metabolic pathway in the rat. MND patients have a defect in their ability to convert cysteine into inorganic sulfate and also show a poor capacity to form the sulfate conjugate of paracetamol. Therefore, these two metabolites may be responsible for neurotoxic effects, resulting in MND-type illness.

In human populations, various investigators have examined the potential association of pesticide exposure with ALS risk. Studies have been conducted in different countries, including Italy (Ferrara, Reggio Emilia, and Sardinia), France (Britanny), USA (states of Massachusetts, Michigan, Minnesota, and Washington), Scotland, Sweden (Scaraborg), Australia (all states), and Greece (Athens), as summarized in Table 1. Included are reports that referred to MND and ALS interchangeably, reports that include ALS as one type of MND, and reports that referred to all MND with no mention of ALS, plus reports that are literature reviews of some of the studies. Table 1 also summarizes the methodological strengths and the weaknesses of these studies. The human studies reported on the potential association of pesticides to ALS, or the lack thereof, are also shown in Table 2. 'Potential association' is based on increased rates or risk in the exposed subjects, suggesting a possible but not definitive role of pesticides, taking into account occupation in an agricultural environment, being 


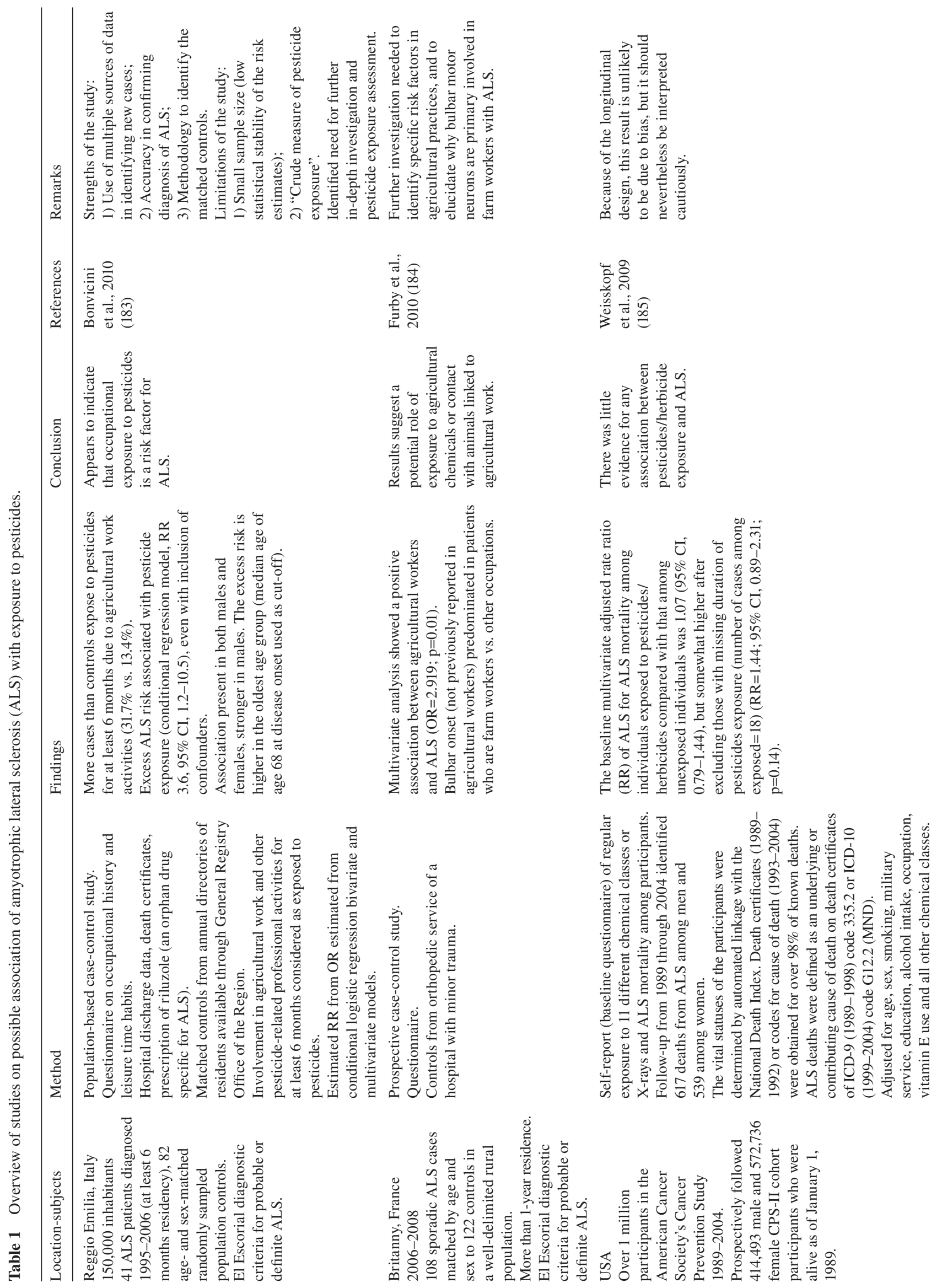



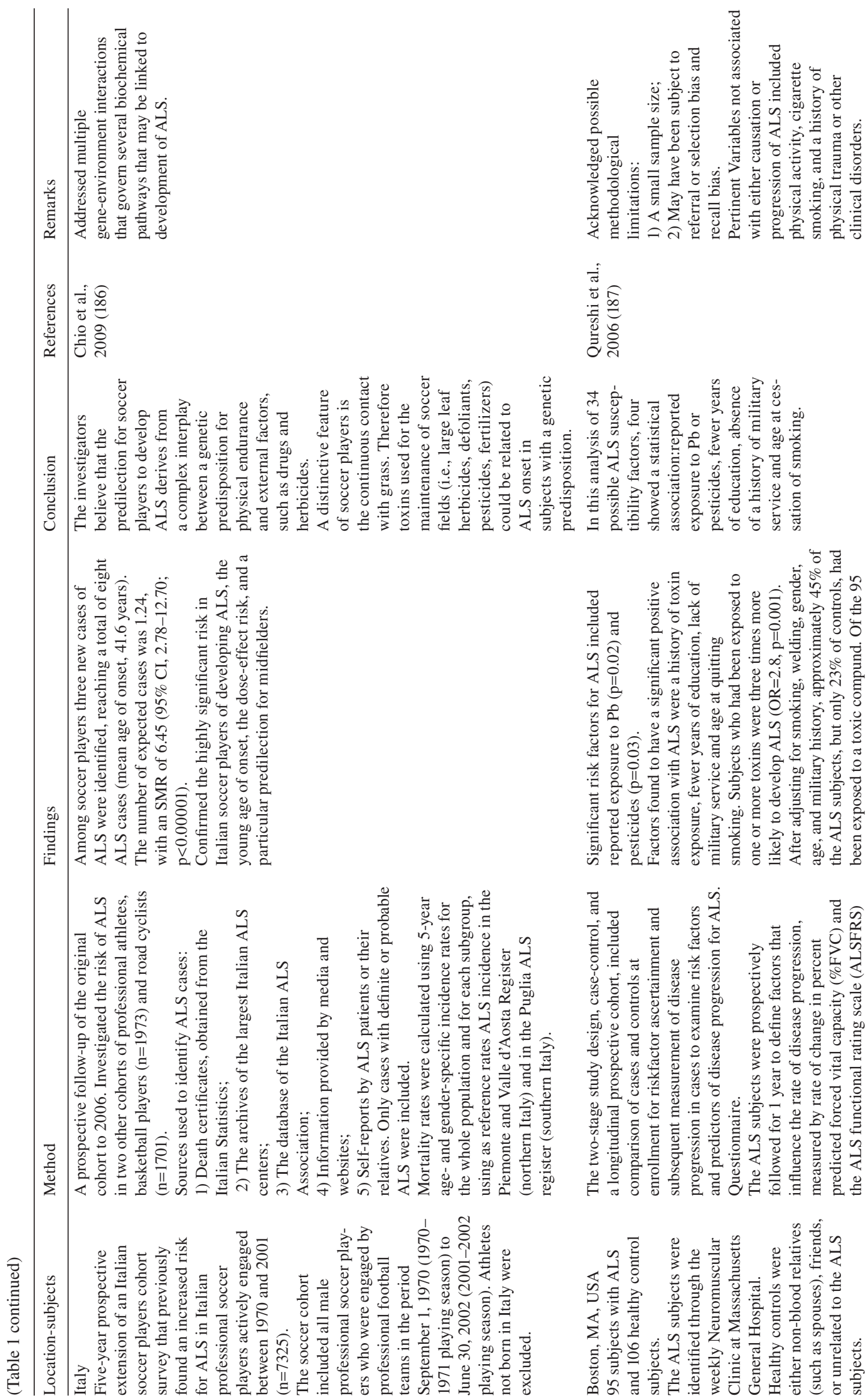

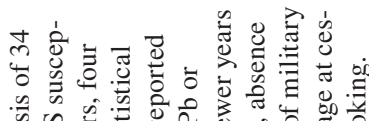

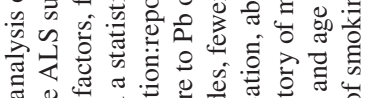

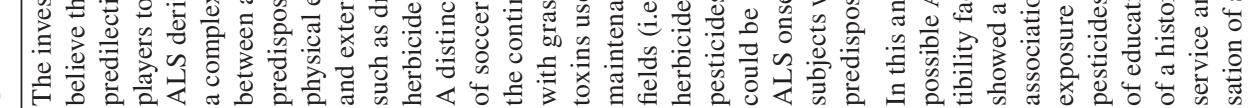

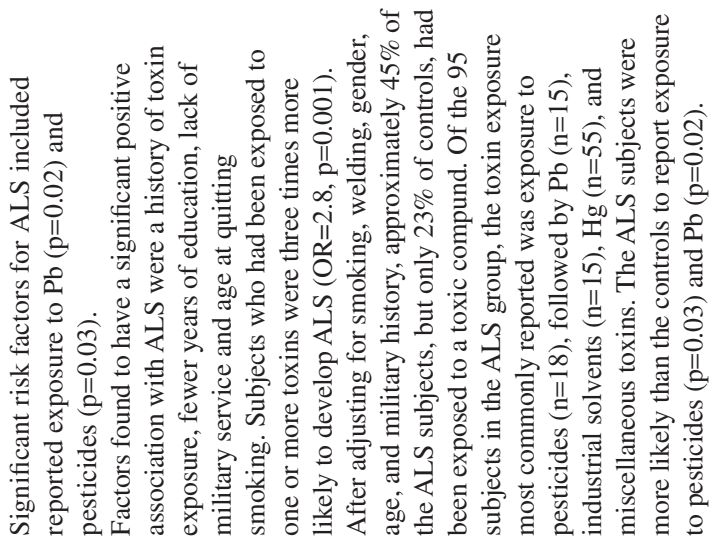

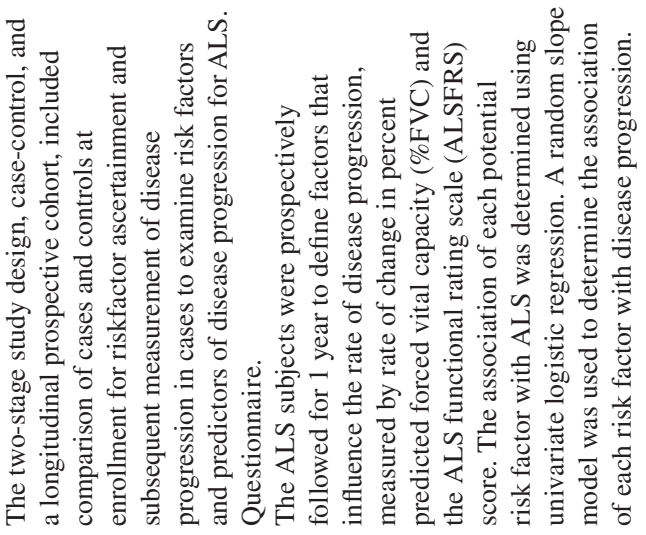

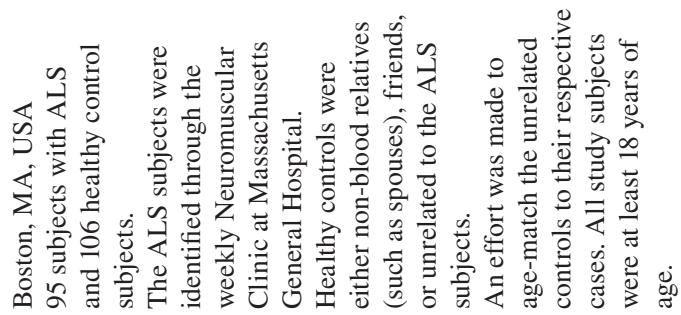




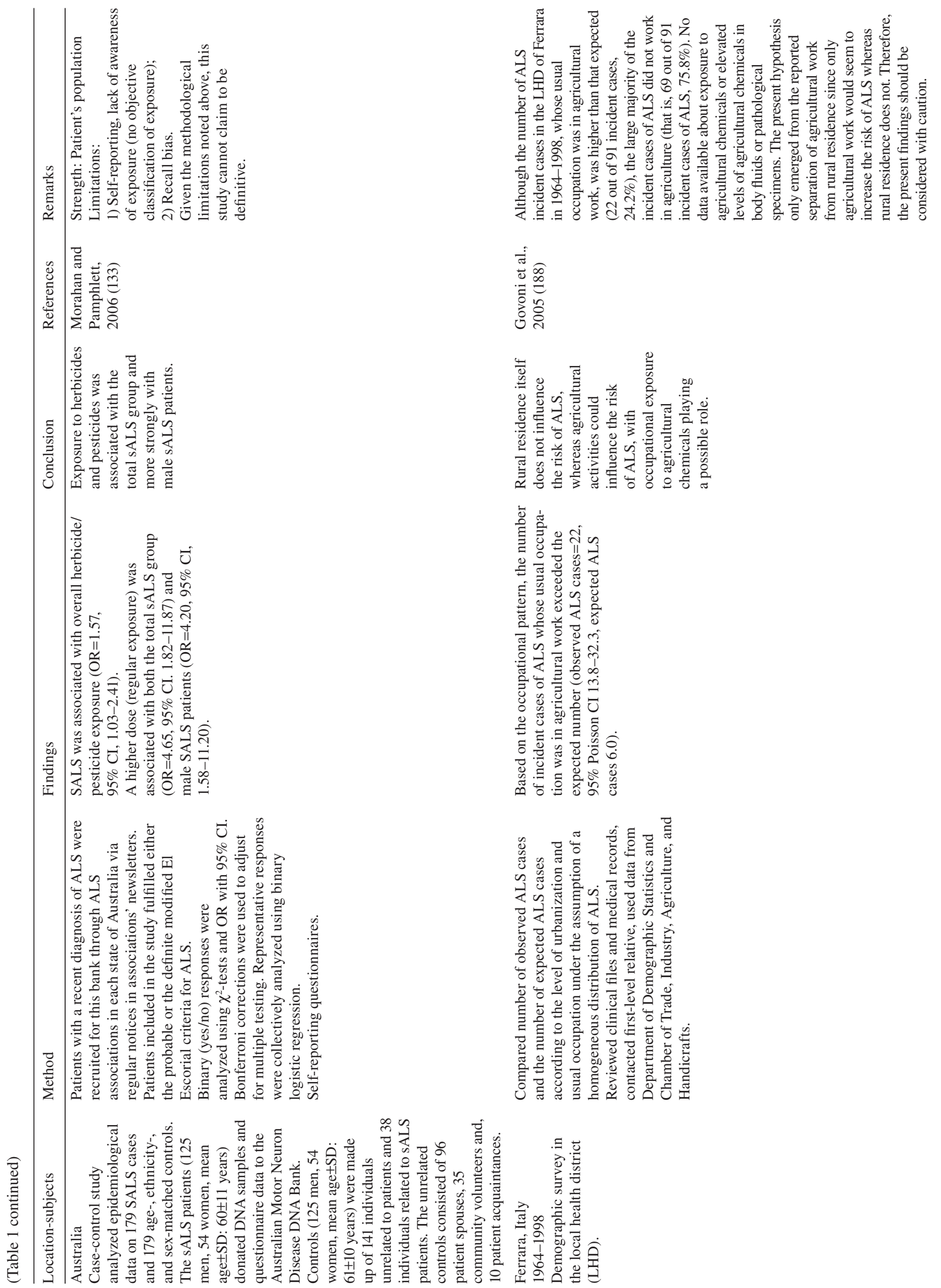




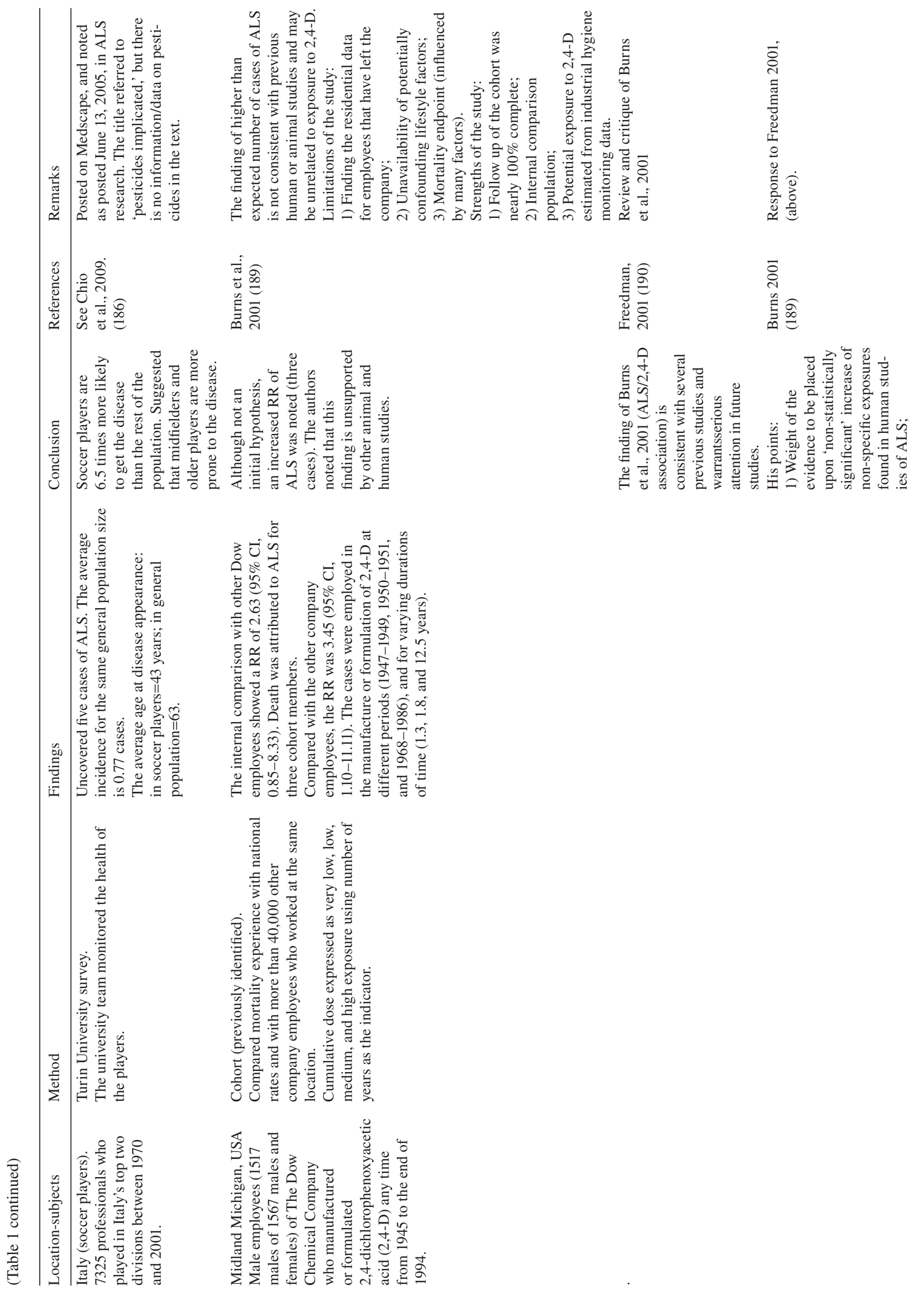




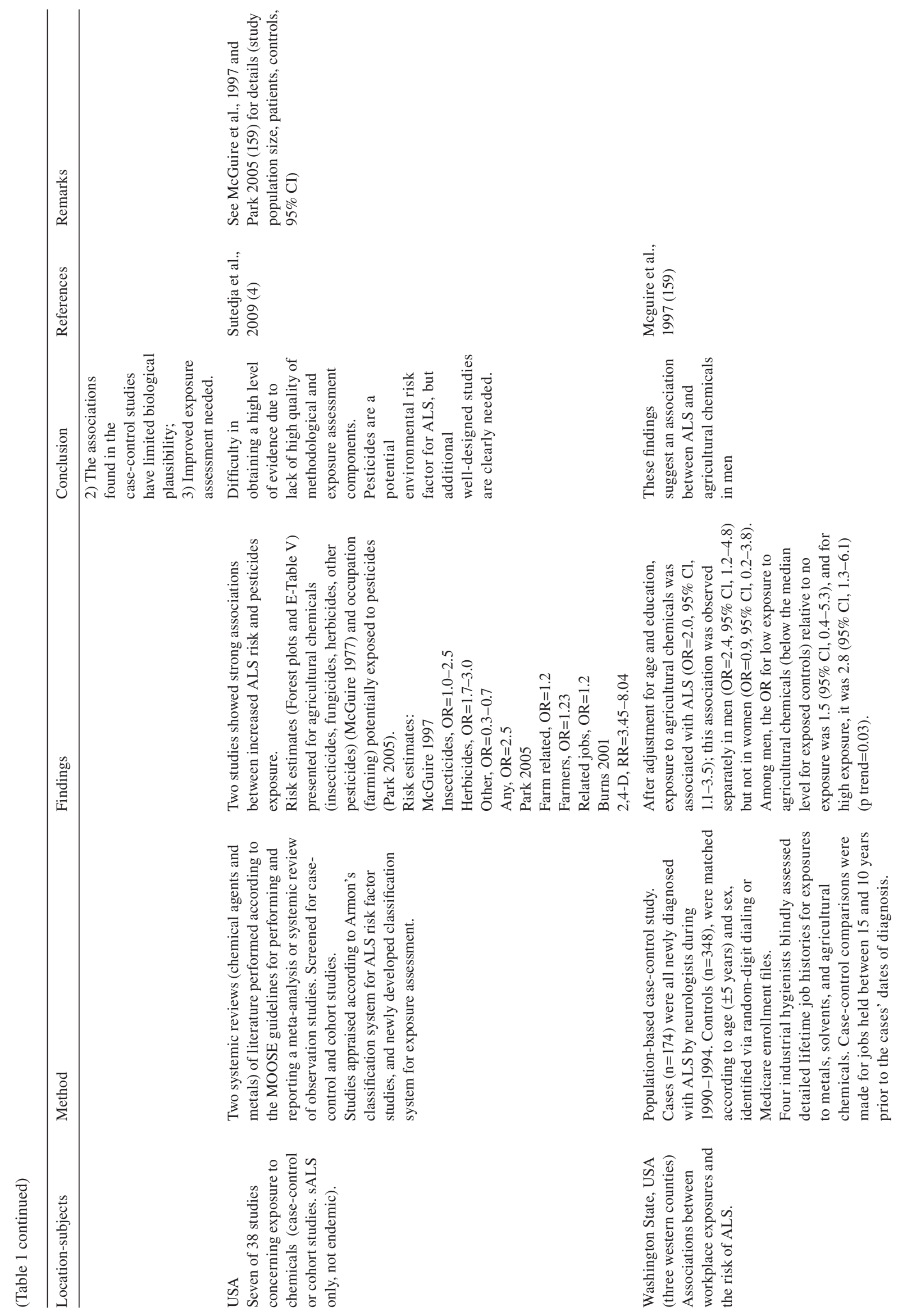

Bereitgestellt von | De Gruyter / TCS (De Gruyter / TCS )

Angemeldet | 172.16.1.226 


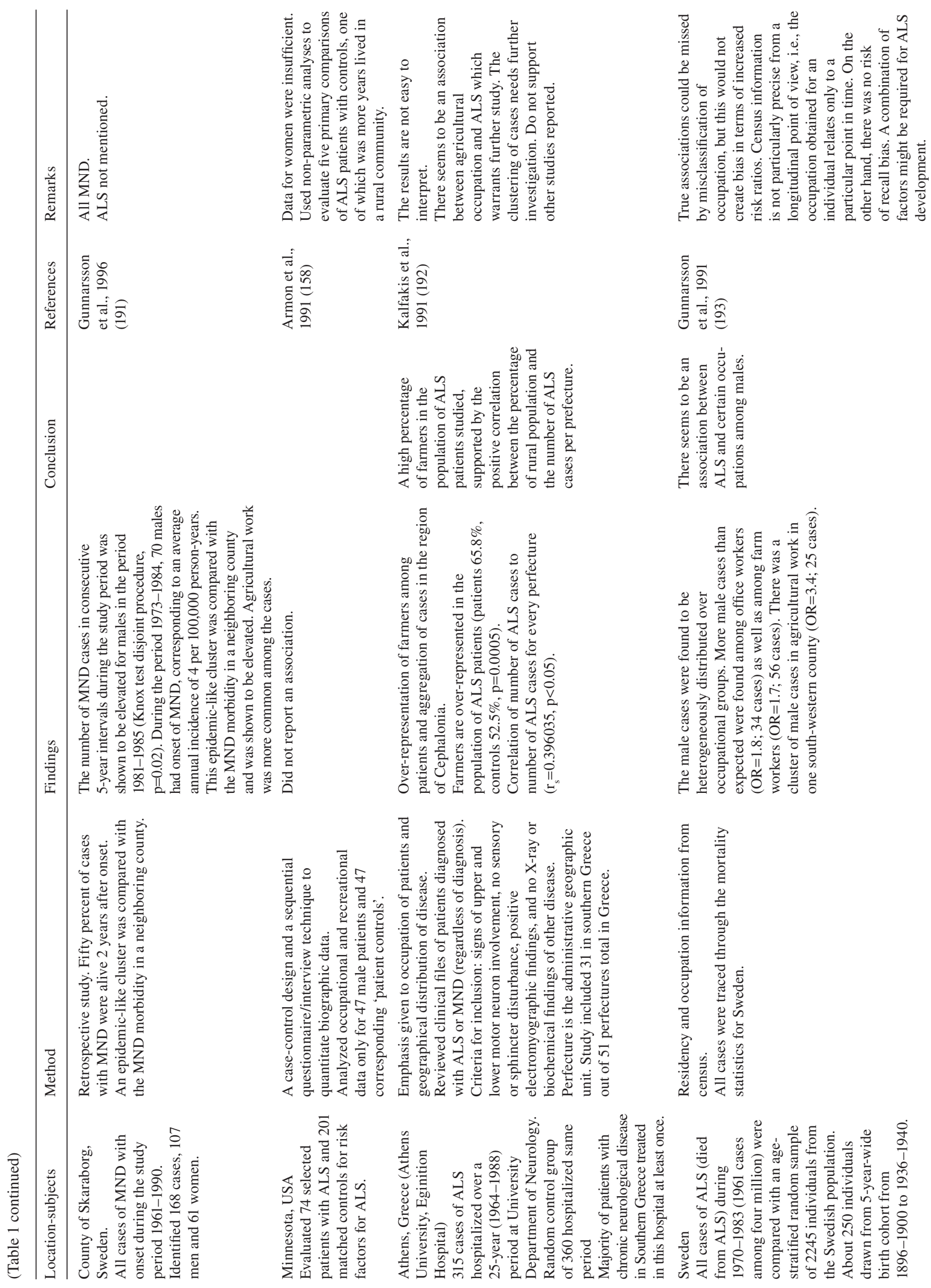




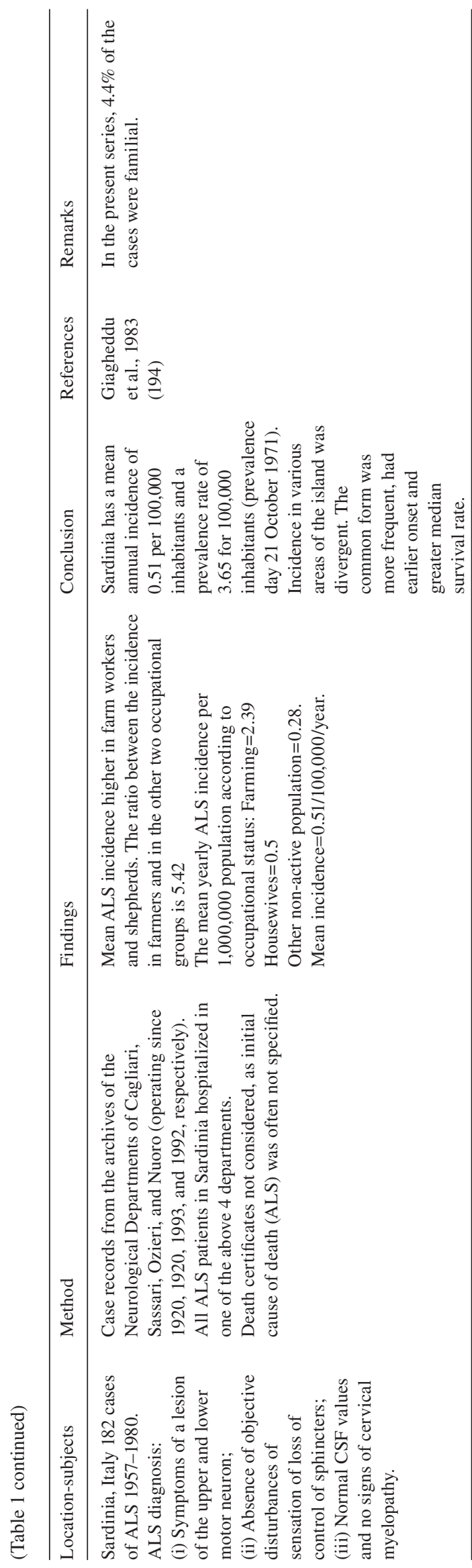

a farmer, or environmental risk factors, such as contact with soccer fields assumed to have been treated with herbicides. The pattern relating ALS to occupational exposure is inconsistent, as, in addition to agriculture and farming, some studies reported associations of ALS with different occupations, such as heavy metal work, electric trauma, use of pneumatic tools, employment in the plastics industry, exposure to heavy metals, acids, and animal carcasses, and truck driving (193). Even when farmers were identified, the subjects might not be the traditional thinking of farmers who use pesticides (e.g., pesticide applications for agricultural crops), but rather sheep breeders as in the case reported by Rosati et al. (196). Of the 18 reports, 13 suggest a weak potential association, and five do not report any association. The potential association is examined mainly in terms of occupation and environmental risk factors, generally using existing records of ALS patients along with control populations and questionnaire surveys. A major weakness of these studies is inadequate exposure assessment due to insufficient information on the actual chemicals involved or about their use (amount, application method), exposure pattern (air, dermal; intermittent; short, medium, or long-term; job category), frequency (hours, daily, monthly), duration (total time period), level of exposure (measured concentrations), industrial hygiene (protective measures). Much of the potential association is assumed (e.g., assumed exposure to pesticides because of agriculture-related work), with no specific pesticide products identified. That the studies were conducted in the different parts of the world offers some level of 'consistency', which is a key aspect of causal inference, although no cause-effect relation was clearly identified. Nevertheless, a suggestion of consistent results can be seen across studies from different areas and different researchers, using different methods and subjects. Other limitations of these studies include small sample size $(183,187)$, unavailable information about confounders, such as lifestyle (e.g., diet, smoking), and other chemical exposures (e.g., chemicals used on farms, in hobbies). Another limitation is the self-reporting nature of certain studies, which might be a subjective process and also may carry recall and selection biases $(133,185,187)$. Therefore, that the increased ALS incidences observed in these studies were actually caused by pesticides cannot be definitively confirmed, although the overall evidence is suggestive of an association between increased ALS risk and pesticide exposure.

As noted above, one potential relation of pesticides to MND is the neurotoxic properties of several pesticides, such as OPs pesticides, and the genetic susceptibility of individuals to such toxicity. As PONs are involved in the detoxification of this group of pesticides, studies have been conducted to examine the potential association between sALS and PON gene cluster variants. Saeed et al. (197) investigated the association between sALS and PON gene cluster variants in a large North American Caucasian family-based and case-control cohort. Clinically definite and probable ALS was diagnosed according to the revised El Escorial criteria, exclusion of family history of ALS, and SOD1 mutation analysis. Singlenucleotide polymorphism (SNP) genotyping was done using TaqMan gene expression assay. A haploblock of high linkage 
Table 2 Summary of reports on human studies on potential association of pesticides to ALS.

\begin{tabular}{|c|c|c|}
\hline References $^{\mathrm{a}}$ & Potential association ${ }^{\mathrm{b}}$ & Characteristics used to link study subjects to pesticides ${ }^{c}$ \\
\hline Bonvicini et al., 2010 (183) & + & Agricultural work \\
\hline Furby et al., 2010 (184) & + & Contact with agricultural chemicals \\
\hline Weisskopf et al., 2009 (185) & - & $\begin{array}{l}\text { No background information (e.g., occupation). American Cancer } \\
\text { Society Cancer Prevention study participants self-reporting on } \\
\text { exposure to } 11 \text { different chemicals classes or X-rays }\end{array}$ \\
\hline Chio et al., 2009 (186) & + & Soccer players \\
\hline Qureshi et al., 2006 (187) & + & $\begin{array}{l}\text { No background information (e.g., occupation). Neuromuscular } \\
\text { clinic patients self -reporting on toxic exposures. }\end{array}$ \\
\hline $\begin{array}{l}\text { Morahan and Pamphlett, } 2006 \\
\text { (133) }\end{array}$ & + & $\begin{array}{l}\text { No background information (e.g., occupation). ALS patients } \\
\text { self-reporting on pesticide/herbicide exposures }\end{array}$ \\
\hline Govoni et al., 2005 (188) & + & Occupation in agricultural work \\
\hline Burns et al., 2001 (189) & + & Manufacture or formulation of 2,4-D \\
\hline McGuire et al., 1997 (159) & + & Exposure to agricultural chemicals (in men) \\
\hline Gunnarsson et al. 1991 (193) & + & Farm workers (and office workers) \\
\hline Giagheddu et al., 1983 (194) & + & Farm workers \\
\hline Holloway et al., 1982 (195) & $\begin{array}{l}+/- \text { (frequency of exposure } \\
9 \% \text { in patients and } 5 \% \text { in the } \\
\text { control population) }\end{array}$ & $\begin{array}{l}\text { Farmers and agricultural workers (including three clinical } \\
\text { variants of MND: progressive muscular atrophy, progressive } \\
\text { bulbar palsy, and ALS). }\end{array}$ \\
\hline Rosati et al., 1977 (196) & + & Agricultural workers, mainly farmers (majority sheep breeders) \\
\hline
\end{tabular}

aThe limitations of the studies are summarized in Table 1 and discussed in the text. ' 'Potential association' (+) is based on increased incidence or RR when the exposed population is compared with the unexposed one, suggesting a possible but not a definitive role of pesticides. ${ }^{c}$ Potential association of pesticides' to ALS is inferred or assumed based on potential association of increased incidence or RR with characteristics that linked study subjects to pesticides, such as occupation in an agricultural environment, being a farmer, or reports on environmental risk factors (e.g., contact with soccer fields assumed to have been treated with herbicides).

disequilibrium (LD) spanning PON2 and PON3 was associated with sALS. The SNPs rs10487132 and rs11981433 were in strong LD and associated with sALS in the trio (parentsaffected child triad) model. The association of rs10487132 was replicated in 450 nuclear pedigrees comprising trios and discordant sibpairs. No association was found in case-control models, and their haplostructure was different from that of the trios with overall reduced LD. Resequencing identified an intronic variant (rs17876088) that differentiates between detrimental and protective sALS haplotypes. The authors concluded that there is an association of variants in the PON gene cluster with sALS, which is compatible with the hypothesis that environmental toxicity in a susceptible host may precipitate ALS.

Some PON1 promoter polymorphisms may predispose to sALS, possibly by making motor neurons more susceptible to OP-containing toxins. To determine whether an impaired ability to break down OPs underlies some cases of sALS, Morahan et al. (177) studied 143 sALS patients and 143 matched controls and compared frequencies of PON1 polymorphisms, investigating gene-environment interactions based on information on self-reported pesticide/herbicide exposure. The PON1 promoter allele 108t, which reduces PON1 expression, was strongly associated with sALS. Overall, promoter haplotypes decreasing PON1 expression were associated with sALS, whereas haplotypes increasing expression were associated with controls.

Wills et al. (178) tested the hypothesis of an association that correlates with functional changes in PON1 (PON1, MIM 168820) within a case-control study. Sera from 140
ALS patients and 153 matched 'healthy' controls and CSF samples from 15 patients and 15 controls were tested for PON, diazoxonase, and arylesterase activities. Participants with ALS were genotyped using tagging SNPs across the PON locus, and survival data and enzyme activity were correlated with genotype. A trend toward increased PON activity was noted in ALS compared with controls, which correlated with increased frequency of the homozygous arginine (RR) variant of PON1Q192R. Contrary to expectations, PON1 protein, PON1, diazoxonase, and arylesterase activities were not reduced in ALS patients. OP hydrolysis rates had no effect on ALS survival. The authors noted that the increase in PON1R192 frequency in ALS in this study supported previous genetic susceptibility studies, and the findings suggested that the influence of PON1 polymorphisms on ALS susceptibility was not due to reduced OPs hydrolysis. A limitation of this study, however, is the lack of a population-based design for cases and controls, an approach that might have been responsible for selection bias.

\section{Conclusions}

Overall, our analysis supports the view that Se and pesticides are likely to be involved, either as triggering factors or as causal agents, in ALS etiology, based on epidemiological evidence and some biological plausibility. The evidence is particularly impressive for Se due to its selective toxicity to motor neurons. Less suggestive is the involvement of $\mathrm{Hg}, \mathrm{Cd}$, or $\mathrm{Pb}$ in disease etiopathogenesis due to the limited evidence from 
both epidemiological and laboratory studies and because the studies carried out thus far are inconclusive. Apart from the PONs genes, little is known about the possible role of genetic susceptibility in mediating the effects of environmental toxins in triggering ALS onset. Various methodological limitations of the studies, such as low statistical power, exposure misclassification, and inadequate control of confounders, might explain the conflicting results found in the literature on these issues. Further in-depth investigation of the involvement of Se, heavy metals, and pesticides in ALS etiology is warranted.

\section{Acknowledgments}

Financial support to this study was provided by Associazione Italiana Sclerosi Laterale Amiotrofica (AISLA), by Pietro Manodori Foundation of Reggio Emilia, and by the Local Health Unit of Reggio Emilia.

\section{References}

1. Naganska E, Matyja E. Amyotrophic lateral sclerosis - looking for pathogenesis and effective therapy. Folia Neuropathol 2011;49:1-13.

2. Georgoulopoulou E, Vinceti M, Bonvicini F, Sola P, Goldoni $\mathrm{CA}$, et al. Changing incidence and subtypes of ALS in Modena, Italy: a 10-years prospective study. Amyotroph Lateral Scler 2011;12:451-7.

3. Uccelli R, Binazzi A, Altavista P, Belli S, Comba P, et al. Geographic distribution of amyotrophic lateral sclerosis through motor neuron disease mortality data. Eur J Epidemiol 2007;22:781-90.

4. Sutedja NA, Veldink JH, Fischer K, Kromhout H, Heederik D, et al. Exposure to chemicals and metals and risk of amyotrophic lateral sclerosis: a systematic review. Amyotroph Lateral Scler 2009;10:302-9.

5. Wijesekera LC, Leigh PN. Amyotrophic lateral sclerosis. Orphanet J Rare Dis 2009;4:3.

6. Callaghan B, Feldman D, Gruis K, Feldman E. The association of exposure to lead, mercury, and selenium and the development of amyotrophic lateral sclerosis and the epigenetic implications. Neurodegener Dis 2011;8:1-8.

7. Fordyce F. Selenium geochemistry and health. Ambio 2007;36:94-7.

8. Bergomi M, Malagoli C, Vinceti M. Selenium deficiency. In: Lang F, editor. Encyclopedia of molecular mechanisms of disease. Berlin: Springer-Verlag, 2009:1914-5.

9. Bergomi M, Malagoli C, Vinceti M. Selenium excess. In: Lang F, editor. Encyclopedia of molecular mechanisms of disease. Berlin: Springer-Verlag, 2009:1915-6.

10. Vinceti M, Maraldi T, Bergomi M, Malagoli C. Risk of chronic low-dose selenium overexposure in humans: insights from epidemiology and biochemistry. Rev Environ Health 2009;24:231-48.

11. Finkelman RB, Belkin HE, Zheng B. Health impacts of domestic coal use in China. Proc Natl Acad Sci USA 1999;96:3427-31.

12. Vinceti M, Wei ET, Malagoli C, Bergomi M, Vivoli G. Adverse health effects of selenium in humans. Rev Environ Health 2001;16:233-51.
13. Pletnikova IP. Biological effect and level of safety of selenium in its entry into the organism with drinking water. Gig Sanit 1970;35:14-9.

14. Nogueira CW, Rocha JB. Toxicology and pharmacology of selenium: emphasis on synthetic organoselenium compounds. Arch Toxicol 2011;85:1313-59.

15. Stranges S, Sieri S, Vinceti M, Grioni S, Guallar E, et al. A prospective study of dietary selenium intake and risk of type 2 diabetes. BMC Public Health 2010;10:564.

16. Laclaustra M, Navas-Acien A, Stranges S, Ordovas JM, Guallar E. Serum selenium concentrations and diabetes in U.S. adults: National Health and Nutrition Examination Survey (NHANES) 2003-2004. Environ Health Perspect 2009;117:1409-13.

17. Klein EA, Thompson IM Jr, Tangen CM, Crowley JJ, Scott Lucia $\mathrm{M}$, et al. Vitamin E and the risk of prostate cancer: the Selenium and Vitamin E Cancer Prevention Trial (SELECT). J Am Med Assoc 2011;306:1549-56.

18. Lin-Shiau SY, Liu SH, Fu WM. Neuromuscular actions of sodium selenite on chick biventer cervicis nerve-muscle preparation. Neuropharmacology 1990;29:493-501.

19. Tsunoda M, Johnson VJ, Sharma RP. Increase in dopamine metabolites in murine striatum after oral exposure to inorganic but not organic form of selenium. Arch Environ Contam Toxicol 2000;39:32-7.

20. Pullen RG, Schofield M, Markham A, Lough J, Menton K. Uptake of 75-selenium into the central nervous system of the rat. Neurochem Res 1995;20:1141-6.

21. Rasekh HR, Soliman KF, Davis MD. Effect of selenium on central nervous system of male S-D rats: evidences for neurotoxicity of selenium. Toxicol Lett 1998;95:64.

22. Islam F, Watanabe Y, Morii H, Hayaishi O. Inhibition of rat brain prostaglandin D synthase by inorganic selenocompounds. Arch Biochem Biophys 1991;289:161-6.

23. Antunes Soares F, Farina M, Boettcher AC, Braga AL, Batista TRJ. Organic and inorganic forms of selenium inhibited differently fish (Rhamdia quelen) and rat (Rattus norvergicus albinus) delta-aminolevulinate dehydratase. Environ Res 2005;98:46-54.

24. Ayaz M, Dalkilic N, Tuncer S, Bariskaner H. Selenium-induced changes on rat sciatic nerve fibers: compound action potentials. Methods Find Exp Clin Pharmacol 2008;30:271-5.

25. El-Demerdash FM. Effects of selenium and mercury on the enzymatic activities and lipid peroxidation in brain, liver, and blood of rats. J Environ Sci Health B 2001;36:489-99.

26. Ardais AP, Viola GG, Costa MS, Nunes F, Behr GA, et al. Acute treatment with diphenyl diselenide inhibits glutamate uptake into rat hippocampal slices and modifies glutamate transporters, SNAP-25, and GFAP immunocontent. Toxicol Sci 2010;113:434-43.

27. Souza AC, Stangherlin EC, Ardais AP, Nogueira CW. Diphenyl diselenide and diphenyl ditelluride: neurotoxic effect in brain of young rats, in vitro. Mol Cell Biochem 2010;340:179-85.

28. Nehru B, Iyer A. Effect of selenium on lead-induced neurotoxicity in different brain regions of adult rats. J Environ Pathol Toxicol Oncol 1994;13:265-8.

29. Xiao R, Qiao JT, Zhao HF, Liang J, Yu HL, et al. Sodium selenite induces apoptosis in cultured cortical neurons with special concomitant changes in expression of the apoptosis-related genes. Neurotoxicology 2006;27:478-84.

30. Zia S, Islam F. Selenium altered the levels of lipids, lipid peroxidation, and sulfhydryl groups in straitum and thalamus of rat. Biol Trace Elem Res 2000;77:251-9.

31. Ammar EM, Couri D. Acute toxicity of sodium selenite and selenomethionine in mice after ICV or IV administration. Neurotoxicology 1981;2:383-6. 
32. Bjorkman L, Mottet K, Nylander M, Vahter M, Lind B, et al. Selenium concentrations in brain after exposure to methylmercury: relations between the inorganic mercury fraction and selenium. Arch Toxicol 1995;69:228-34.

33. Kasuya M. Effect of selenium on the toxicity of methylmercury on nervous tissue in culture. Toxicol Appl Pharmacol 1976;35:11-20.

34. Glaser V, Nazari EM, Muller YM, Feksa L, Wannmacher CM, et al. Effects of inorganic selenium administration in methylmercury-induced neurotoxicity in mouse cerebral cortex. Int J Dev Neurosci 2010;28:631-7.

35. Maraldi T, Riccio M, Zambonin L, Vinceti M, De Pol A, et al. Low levels of selenium compounds are selectively toxic for a human neuron cell line through ROS/RNS increase and apoptotic process activation. Neurotoxicology 2011;32:180-7.

36. Magrane J, Manfredi G. Mitochondrial function, morphology, and axonal transport in amyotrophic lateral sclerosis. Antioxid Redox Signal 2009;11:1615-26.

37. Togna G, Russo P, Pierconti F, Caprino L. Effects of sodium selenite on vascular smooth muscle reactivity. Pharmacol Res 2000;41:195-9.

38. Gupta N, Porter TD. Inhibition of human squalene monooxygenase by selenium compounds. J Biochem Mol Toxicol 2002;16:18-23.

39. Wagner M, Toews AD, Morell P. Tellurite specifically affects squalene epoxidase: investigations examining the mechanism of tellurium-induced neuropathy. J Neurochem 1995;64:2169-76.

40. Herigstad RR, Whitechair CK, Olson OE. Inorganic and organic selenium toxicosis in young swine: comparison of pathologic changes with those in seine with vitamin E-selenium deficiency. Am J Vet Res 1973;34:1227-38.

41. Harrison LH, Colvin BM, Stuart BP, Sangster LT, Gorgacz EJ, et al. Paralysis in swine due to focal symmetrical poliomalacia: possible selenium toxicosis. Vet Pathol 1983;20:265-73.

42. Wilson TM, Scholz RW, Drake TR. Selenium toxicity and porcine focal symmetrical poliomyelomalacia: description of a field outbreak and experimental reproduction. Can J Comp Med 1983;47:412-21.

43. Casteignau A, Fontan A, Morillo A, Oliveros JA, Segales J. Clinical, pathological and toxicological findings of a iatrogenic selenium toxicosis case in feeder pigs. J Vet Med A Physiol Pathol Clin Med 2006;53:323-6.

44. Nathues H, Boehne I, grosse Beilage T, Gerhauser I, HewickerTrautwein $\mathrm{M}$, et al. Peracute selenium toxicosis followed by sudden death in growing and finishing pigs. Can Vet $\mathrm{J}$ 2010;51:515-8.

45. Raber M, Sydler T, Wolfisberg U, Geyer H, Burgi E. Feedrelated selenium poisoning in swine. Schweiz Arch Tierheilkd 2010;152:245-52.

46. Panter KE, Hartley WJ, James LF, Mayland HF, Stegelmeier BL, et al. Comparative toxicity of selenium from seleno-DL-methionine, sodium selenate, and Astragalus bisulcatus in pigs. Fund Appl Toxicol 1996;32:217-23.

47. Maag DD, Orsborn JS, Clopton JR. The effect of sodium selenite on cattle. Am J Vet Res 1960;21:1049-53.

48. Liu SH, Fu WM, Lin-Shiau SY. Effects of sodium selenite on neuromuscular junction of the mouse phrenic nerve-diaphragm preparation. Neuropharmacology 1989;28:733-9.

49. Morgan KL, Estevez AO, Mueller CL, Cacho-Valadez B, Miranda-Vizuete A, et al. The glutaredoxin GLRX-21 functions to prevent selenium-induced oxidative stress in Caenorhabditis elegans. Toxicol Sci 2010;118:530-43.
50. Nogueira CW, Meotti FC, Curte E, Pilissao C, Zeni G, et al. Investigations into the potential neurotoxicity induced by diselenides in mice and rats. Toxicology 2003;183:29-37.

51. Kilness AW, Hochberg FH. Amyotrophic lateral sclerosis in a high selenium environment. J Am Med Assoc 1977;237:2843-4.

52. Mitchell JD, East BW, Harris IA, Pentland B. Manganese, selenium and other trace elements in spinal cord, liver and bone in motor neurone disease. Eur Neurol 1991;31:7-11.

53. Ince PG, Shaw PJ, Candy JM, Mantle D, Tandon L, et al. Iron, selenium and glutathione peroxidase activity are elevated in sporadic motor neuron disease. Neurosci Lett 1994;182:87-90.

54. Vinceti M, Guidetti D, Bergomi M, Caselgrandi E, Vivoli R, et al. Lead, cadmium, and selenium in the blood of patients with sporadic amyotrophic lateral sclerosis. Ital J Neurol Sci 1997; 18:87-92.

55. Bergomi M, Vinceti M, Nacci G, Pietrini V, Bratter P, et al. Environmental exposure to trace elements and risk of amyotrophic lateral sclerosis: a population-based case-control study. Environ Res 2002;89:116-23.

56. Yang GQ, Wang SZ, Zhou RH, Sun SZ. Endemic selenium intoxication of humans in China. Am J Clin Nutr 1983;37:872-81.

57. Technical report WC/96/7R. Report of field visit and initial data from investigations into the prediction and remediation of human selenium imbalances in Enshi District, Hubei Province, China 8-16 November 1995. British Geological Survey. Available from http:// www.bgs.ac.uk/research/international/dfid-kar/WC96007R_col. pdf. Accessed March 14, 2012.

58. Lemire M, Philibert A, Fillion M, Passos CJ, Guimaraes JR, et al. No evidence of selenosis from a selenium-rich diet in the Brazilian Amazon. Environ Int 2012;40:128-36.

59. Saint-Amour D, Roy MS, Bastien C, Ayotte P, Dewailly E, et al. Alterations of visual evoked potentials in preschool Inuit children exposed to methylmercury and polychlorinated biphenyls from a marine diet. Neurotoxicology 2006;27:567-78.

60. Vinceti M, Guidetti D, Pinotti M, Rovesti S, Merlin M, et al. Amyotrophic lateral sclerosis after long-term exposure to drinking water with high selenium content. Epidemiology 1996; 7:529-32.

61. Vinceti M, Bonvicini F, Rothman KJ, Vescovi L, Wang F. The relation between amyotrophic lateral sclerosis and inorganic selenium in drinking water: a population-based case-control study. Environ Health 2010;9:77.

62. Vinceti M, Rothman KJ, Bergomi M, Borciani N, Serra L, et al. Excess melanoma incidence in a cohort exposed to high levels of environmental selenium. Cancer Epidemiol Biomarkers Prev 1998; 7:853-6.

63. Vinceti M, Nacci G, Rocchi E, Cassinadri T, Vivoli R, et al. Mortality in a population with long-term exposure to inorganic selenium via drinking water. J Clin Epidemiol 2000;53:1062-8.

64. Vinceti M, Rovesti S, Gabrielli C, Marchesi C, Bergomi M, et al. Cancer mortality in a residential cohort exposed to environmental selenium through drinking water. J Clin Epidemiol 1995;48:1091-7.

65. Vinceti M, Rovesti S, Marchesi C, Bergomi M, Vivoli G. Changes in drinking water selenium and mortality for coronary disease in a residential cohort. Biol Trace Elem Res 1994;40:267-75.

66. Orrell RW, Lane RJ, Ross M. Antioxidant treatment for amyotrophic lateral sclerosis/motor neuron disease. Cochrane Database Syst Rev 2007;1:CD002829.

67. Hunter DBRR, Russel DS. Poisoning by methyl mercury compounds. Q J Med 1940;9:193-219. 
68. Takeuchi T, Kambara T, Morikawa N, Matsumoto H, Shiraishi Y, et al. Pathologic observations of the Minamata disease. Acta Pathol Jpn 1959;9(Suppl):769-83.

69. Johnson FO, Atchison WD. The role of environmental mercury, lead and pesticide exposure in development of amyotrophic lateral sclerosis. Neurotoxicology 2009;30:761-5.

70. Schmidtke K. [Mercury and Alzheimer's disease]. Fortschr Neurol Psychiatr 2007;75:508-9.

71. Koren G, Bend JR. Fish consumption in pregnancy and fetal risks of methylmercury toxicity. Can Fam Physician 2010;56:1001-2.

72. Finkelstein Y, Vardi J, Kesten MM, Hod I. The enigma of parkinsonism in chronic borderline mercury intoxication, resolved by challenge with penicillamine. Neurotoxicology 1996;17:291-5.

73. Berlin M, Ullrebg S. Increased uptake of mercury in mouse brain caused by 2,3-dimercaptopropanol. Nature 1963;197:84-5.

74. Berlin M, Ullberg S. Accumulation and retention of mercury in the mouse. I. An autoradiographic study after a single intravenous injection of mercuric chloride. Arch Environ Health 1963;6:589-601.

75. Berlin M, Ullberg S. Accumulation and retention of mercury in the mouse. II. An autoradiographic comparison of phenylmercuric acetate with inorganic mercury. Arch Environ Health 1963;6:602-9.

76. Berlin M, Ullberg S. Accumulation and retention of mercury in the mouse. III. An autoradiographic comparison of methylmercuric dicyandiamide with inorganic mercury. Arch Environ Health 1963;6:610-6.

77. Miyakawa T, Deshimaru M. Electron microscopical study of experimentally induced poisoning due to organic mercury compound. Mechanisof development of the morbid change. Acta Neuropathol 1969;14:126-36.

78. Miyakawa T, Deshimaru M, Sumiyoshi S, Teraoka A, Udo N, et al. Experimental organic mercury poisoning - pathological changes in peripheral nerves. Acta Neuropathol 1970;15:45-55.

79. Chang LW, Desnoyers PA, Hartmann HA. Quantitative cytochemical studies of RNA in experimental mercury poisoning. Changes in RNA content. J Neuropathol Exp Neurol 1972;31:489-501.

80. Chang LW, Martin AH, Hartmann HA. Quantitative autoradiographic study on the RNA synthesis in the neurons after mercury intoxication. Exp Neurol 1972;37:62-7.

81. Passow H. [Ion permeability of red blood cells]. Bibl Haematol 1961;12:111-36.

82. Steinwall O, Klatzo I. Selective vulnerability of the blood-brain barrier in chemically induced lesions. J Neuropathol Exp Neurol 1966;25:542-59.

83. Steinwall O. Brain uptake of Se75-selenomethionine after damage to blood-brain barrier by mercuric ions. Acta Neurol Scand 1969;45:362-8.

84. Steinwall O, Olsson Y. Impairment of the blood-brain barrier in mercury poisoning. Acta Neurol Scand 1969;45:351-61.

85. Yoshino Y, Mozai T, Nakao K. Biochemical changes in the brain in rats poisoned with an alkymercury compound, with special reference to the inhibition of protein synthesis in brain cortex slices. J Neurochem 1966;13:1223-30.

86. Cavanagh JB, Chen FC. Amino acid incorporation in protein during the "silent phase" before organo-mercury and p-bromophenylacetylurea neuropathy in the rat. Acta Neuropathol 1971;19:216-24.

87. Cavanagh JB, Chen FC. The effects of methyl-mercury-dicyandiamide on the peripheral nerves and spinal cord of rats. Acta Neuropathol 1971;19:208-15.

88. Chang LW, Ware RA, Desnoyers PA. A histochemical study on some enzyme changes in the kidney, liver and brain after chronic mercury intoxication in the rat. Food Cosmet Toxicol 1973;11:283-6.

89. Paterson RA, Usher DR. Acute toxicity of methyl mercury on glycolytic intermediates and adenine nucleotides of rat brain. Life Sci II 1971;10:121-8.

90. Shaw PJ. Molecular and cellular pathways of neurodegeneration in motor neurone disease. J Neurol Neurosurg Psychiatry 2005;76:1046-57.

91. Mackenzie IR, Bigio EH, Ince PG, Geser F, Neumann M, et al. Pathological TDP-43 distinguishes sporadic amyotrophic lateral sclerosis from amyotrophic lateral sclerosis with SOD1 mutations. Ann Neurol 2007;61:427-34.

92. Neumann M, Kwong LK, Lee EB, Kremmer E, Flatley A, et al. Phosphorylation of S409/410 of TDP-43 is a consistent feature in all sporadic and familial forms of TDP-43 proteinopathies. Acta Neuropathol 2009;117:137-49.

93. Pamphlett R, Luquin N, McLean C, Jew SK, Adams L. TDP-43 neuropathology is similar in sporadic amyotrophic lateral sclerosis with or without TDP-43 mutations. Neuropathol Appl Neurobiol 2009;35:222-5.

94. Pamphlett R, Jew SK. Inorganic mercury within motor neurons does not cause the TDP-43 changes seen in sporadic ALS. Toxicol Lett 2011;201:58-61.

95. Mackenzie IR, Rademakers R, Neumann M. TDP-43 and FUS in amyotrophic lateral sclerosis and frontotemporal dementia. Lancet Neurol 2010;9:995-1007.

96. Chuu JJ, Liu SH, Lin-Shiau SY. Differential neurotoxic effects of methylmercury and mercuric sulfide in rats. Toxicol Lett 2007;169:109-20.

97. Somjen GG, Herman SP, Klein R. Electrophysiology of methyl mercury poisoning. J Pharmacol Exp Ther 1973;186:579-92.

98. Somjen GG, Herman SP, Klein R, Brubaker PE, Briner WH, et al. The uptake of methyl mercury $(203 \mathrm{Hg})$ in different tissues related to its neurotoxic effects. J Pharmacol Exp Ther 1973;187:602-11.

99. Shrivastav BB, Brodwick BS, Narahashi T. Methylmercury: effects on electrical properties of squid axon membranes. Life Sci 1976;18:1077-81.

100. Brown IA. Chronic mercurialism; a cause of the clinical syndrome of amyotrophic lateral sclerosis. AMA Arch Neurol Psychiatry 1954;72:674-81.

101. Barber TE. Inorganic mercury intoxication reminiscent of amyotrophic lateral sclerosis. J Occup Med 1978;20:667-9.

102. Adams CR, Ziegler DK, Lin JT. Mercury intoxication simulating amyotrophic lateral sclerosis. J Am Med Assoc 1983;250:642-3

103. Praline J, Guennoc AM, Limousin N, Hallak H, de Toffol B, et al. ALS and mercury intoxication: a relationship? Clin Neurol Neurosurg 2007;109:880-3.

104. Gresham LS, Molgaard CA, Golbeck AL, Smith R. Amyotrophic lateral sclerosis and occupational heavy metal exposure: a casecontrol study. Neuroepidemiology 1986;5:29-38.

105. Moriwaka F, Satoh H, Ejima A, Watanabe C, Tashiro K, et al. Mercury and selenium contents in amyotrophic lateral sclerosis in Hokkaido, the northernmost island of Japan. J Neurol Sci 1993;118:38-42.

106. Jarup L, Akesson A. Current status of cadmium as an environmental health problem. Toxicol Appl Pharmacol 2009;238:201-8.

107. Klaassen CD, Liu J, Choudhuri S. Metallothionein: an intracellular protein to protect against cadmium toxicity. Annu Rev Pharmacol Toxicol 1999;39:267-94.

108. Nordberg GF. Cadmium and health in the 21 st century - historical remarks and trends for the future. Biometals 2004;17:485-9. 
109. Huang YH, Shih CM, Huang CJ, Lin CM, Chou CM, et al. Effects of cadmium on structure and enzymatic activity of $\mathrm{Cu}, \mathrm{Zn}-\mathrm{SOD}$ and oxidative status in neural cells. J Cell Biochem 2006;98:577-89.

110. Ali I, Penttinen-Damdimopoulou PE, Makela SI, Berglund M, Stenius U, et al. Estrogen-like effects of cadmium in vivo do not appear to be mediated via the classical estrogen receptor transcriptional pathway. Environ Health Perspect 2010;118:1389-94.

111. Johnson MD, Kenney N, Stoica A, Hilakivi-Clarke L, Singh B, et al. Cadmium mimics the in vivo effects of estrogen in the uterus and mammary gland. Nat Med 2003;9:1081-4.

112. Henson MC, Chedrese PJ. Endocrine disruption by cadmium, a common environmental toxicant with paradoxical effects on reproduction. Exp Biol Med (Maywood) 2004;229:383-92.

113. IARC Monographs on the Evaluation of Carcinogenic Risks to Humans. Beryllium, cadmium, mercury, and exposures in the glass manufacturing industry. Lyon, France: World Health Organization, International Agency for Research on Cancer, 1993.

114. Joseph P. Mechanisms of cadmium carcinogenesis. Toxicol Appl Pharmacol 2009;238:272-9.

115. Waalkes MP. Cadmium carcinogenesis. Mutat Res 2003;533:107-20.

116. Price-Haughey J, Bonham K, Gedamu L. Heavy metal-induced gene expression in fish and fish cell lines. Environ Health Perspect 1986;65:141-7.

117. Van Campenhout K, Infante HG, Adams F, Blust R. Induction and binding of $\mathrm{Cd}, \mathrm{Cu}$, and $\mathrm{Zn}$ to metallothionein in carp (Cyprinus carpio) using HPLC-ICP-TOFMS. Toxicol Sci 2004;80:276-87.

118. Casalino E, Calzaretti G, Sblano C, Landriscina C. Molecular inhibitory mechanisms of antioxidant enzymes in rat liver and kidney by cadmium. Toxicology 2002;179:37-50.

119. Dokholyan NV, Ding F. Dynamical roles of metal ions and the disulfide bond in $\mathrm{Cu}, \mathrm{Zn}$ superoxide dismutase folding and aggregation. Proc Natl Acad Sci USA 2008;105:19696-701.

120. Watanabe M, Dykes-Hoberg M, Culotta VC, Price DL, Wong $\mathrm{PC}$, et al. Histological evidence of protein aggregation in mutant SOD1 transgenic mice and in amyotrophic lateral sclerosis neural tissues. Neurobiol Dis 2001;8:933-41.

121. Chan PK, Cheng SH. Cadmium-induced ectopic apoptosis in zebrafish embryos. Arch Toxicol 2003;77:69-79.

122. Ferm VH. Developmental malformations induced by cadmium. A study of timed injections during embryogenesis. Biol Neonate 1971;19:101-7.

123. Nakashima K, Kawamata A, Matsuoka M, Wakisaka T, Fujiki Y. [Dose-response relationship of cadmium or radiation-induced embryotoxicity in mouse whole embryo culture]. Gifu Shika Gakkai Zasshi 1988;15:412-9.

124. Pamphlett R, McQuilty R, Zarkos K. Blood levels of toxic and essential metals in motor neuron disease. Neurotoxicology 2001;22:401-10.

125. Bar-Sela S, Reingold S, Richter ED. Amyotrophic lateral sclerosis in a battery-factory worker exposed to cadmium. Int $\mathrm{J}$ Occup Environ Health 2001;7:109-12.

126. Kjellstrom T, Nordberg GF. A kinetic model of cadmium metabolism in the human being. Environ Res 1978;16:248-69.

127. Bar-Sela S, Levy M, Westin JB, Laster R, Richter ED. Medical findings in nickel-cadmium battery workers. Isr J Med Sci 1992;28:578-83.

128. Fang F, Quinlan P, Ye W, Barber MK, Umbach DM, et al. Workplace exposures and the risk of amyotrophic lateral sclerosis. Environ Health Perspect 2009;117:1387-92.
129. Roelofs-Iverson RA, Mulder DW, Elveback LR, Kurland LT, Molgaard CA. ALS and heavy metals: a pilot case-control study. Neurology 1984;34:393-5.

130. Kasarskis EJ, Ehmann WD, Markesbery WR. Trace metals in human neurodegenerative diseases. Prog Clin Biol Res 1993;380:299-310.

131. Chancellor AM, Slattery JM, Fraser H, Warlow CP. Risk factors for motor neuron disease: a case-control study based on patients from the Scottish Motor Neuron Disease Register. J Neurol Neurosurg Psychiatry 1993;56:1200-6.

132. Pierce-Ruhland R, Patten BM. Repeat study of antecedent events in motor neuron disease. Ann Clin Res 1981;13:102-7.

133. Morahan JM, Pamphlett R. Amyotrophic lateral sclerosis and exposure to environmental toxins: an Australian case-control study. Neuroepidemiology 2006;27:130-5.

134. Sillevis Smitt PA, van Beek H, Baars AJ, Troost D, Louwerse ES, et al. Increased metallothionein in the liver and kidney of patients with amyotrophic lateral sclerosis. Arch Neurol 1992;49:721-4.

135. Patrick L. Lead toxicity, a review of the literature. Part 1: exposure, evaluation, and treatment. Altern Med Rev 2006;11:2-22.

136. Finkelstein Y, Markowitz ME, Rosen JF. Low-level leadinduced neurotoxicity in children: an update on central nervous system effects. Brain Res Brain Res Rev 1998;27:168-76.

137. Hu H, Rabinowitz M, Smith D. Bone lead as a biological marker in epidemiologic studies of chronic toxicity: conceptual paradigms. Environ Health Perspect 1998;106:1-8.

138. Kiernan MC, Vucic S, Cheah BC, Turner MR, Eisen A, et al. Amyotrophic lateral sclerosis. Lancet 2011;377:942-55.

139. Bruijn LI, Houseweart MK, Kato S, Anderson KL, Anderson $\mathrm{SD}$, et al. Aggregation and motor neuron toxicity of an ALSlinked SOD1 mutant independent from wild-type SOD1. Science 1998;281:1851-4.

140. Staats KA, Van Den Bosch L. Astrocytes in amyotrophic lateral sclerosis: direct effects on motor neuron survival. J Biol Phys 2009;35:337-46.

141. Sreedharan J, Blair IP, Tripathi VB, Hu X, Vance C, et al. TDP-43 mutations in familial and sporadic amyotrophic lateral sclerosis. Science 2008;319:1668-72.

142. Vance C, Rogelj B, Hortobagyi T, De Vos KJ, Nishimura $\mathrm{AL}$, et al. Mutations in FUS, an RNA processing protein, cause familial amyotrophic lateral sclerosis type 6 . Science 2009;323:1208-11.

143. Kamel F, Umbach DM, Munsat TL, Shefner JM, Hu H, et al. Lead exposure and amyotrophic lateral sclerosis. Epidemiology 2002;13:311-9.

144. Boillee S, Yamanaka K, Lobsiger CS, Copeland NG, Jenkins NA, et al. Onset and progression in inherited ALS determined by motor neurons and microglia. Science 2006;312:1389-92.

145. Tiffany-Castiglioni E. Cell culture models for lead toxicity in neuronal and glial cells. Neurotoxicology 1993;14:513-36.

146. Tiffany-Castiglioni E, Guerri C, Aschner M, Matsushima GK, O'Callaghan JP, et al. Roles of glia in developmental neurotoxicity: session VI summary and research needs. Neurotoxicology 2001;22:567-73.

147. Cabell L, Ferguson C, Luginbill D, Kern M, Weingart A, et al. Differential induction of heme oxygenase and other stress proteins in cultured hippocampal astrocytes and neurons by inorganic lead. Toxicol Appl Pharmacol 2004;198:49-60.

148. Barbeito AG, Martinez-Palma L, Vargas MR, Pehar M, Manay $\mathrm{N}$, et al. Lead exposure stimulates VEGF expression in the spinal cord and extends survival in a mouse model of ALS. Neurobiol Dis 2010;37:574-80. 
149. Barbeito LH, Pehar M, Cassina P, Vargas MR, Peluffo H, et al. A role for astrocytes in motor neuron loss in amyotrophic lateral sclerosis. Brain Res Brain Res Rev 2004;47:263-74.

150. Babu MS, Gopal NV, Reddy KP. Post natal antioxidant enzyme activity of rat brain regions during developmental lead exposure. J Environ Biol 2007;28:21-7.

151. Kamel F, Umbach DM, Stallone L, Richards M, Hu H, et al. Association of lead exposure with survival in amyotrophic lateral sclerosis. Environ Health Perspect 2008;116:943-7.

152. Fang F, Kwee LC, Allen KD, Umbach DM, Ye W, et al. Association between blood lead and the risk of amyotrophic lateral sclerosis. Am J Epidemiol 2010;171:1126-33.

153. Kamel F, Umbach DM, Hu H, Munsat TL, Shefner JM, et al. Lead exposure as a risk factor for amyotrophic lateral sclerosis. Neurodegener Dis 2005;2:195-201.

154. Campbell AM, Williams ER, Barltrop D. Motor neurone disease and exposure to lead. J Neurol Neurosurg Psychiatry 1970;33:877-85.

155. Aran FA. Recherches sur une maladie non encore décrite du système musculaire (Atrophie musculaire progressive). Arch Gen Med 1850;4:4-35.

156. Oh SS, Kim EA, Lee SW, Kim MK, Kang SK. A case of amyotrophic lateral sclerosis in electronic parts manufacturing worker exposed to lead. Neurotoxicology 2007;28:324-7.

157. Felmus MT, Patten BM, Swanke L. Antecedent events in amyotrophic lateral sclerosis. Neurology 1976;26:167-72.

158. Armon C, Kurland LT, Daube JR, O'Brien PC. Epidemiologic correlates of sporadic amyotrophic lateral sclerosis. Neurology 1991;41:1077-84.

159. McGuire V, Longstreth WT Jr, Nelson LM, Koepsell TD, Checkoway $\mathrm{H}$, et al. Occupational exposures and amyotrophic lateral sclerosis. A population-based case-control study. Am J Epidemiol 1997;145:1076-88.

160. Bharucha NE, Schoenberg BS, Raven RH, Pickle LW, Byar DP, et al. Geographic distribution of motor neuron disease and correlation with possible etiologic factors. Neurology 1983;33:911-5.

161. Deapen DM, Henderson BE. A case-control study of amyotrophic lateral sclerosis. Am J Epidemiol 1986;123:790-9.

162. Scarpa M, Colombo A, Panzetti P, Sorgato P. Epidemiology of amyotrophic lateral sclerosis in the province of Modena, Italy. Influence of environmental exposure to lead. Acta Neurol Scand 1988;77:456-60.

163. Mandrioli J, Faglioni P, Merelli E, Sola P. The epidemiology of ALS in Modena, Italy. Neurology 2003;60:683-9.

164. Guidetti D, Bondavalli M, Sabadini R, Marcello N, Vinceti $\mathrm{M}$, et al. Epidemiological survey of amyotrophic lateral sclerosis in the province of Reggio Emilia, Italy: influence of environmental exposure to lead. Neuroepidemiology 1996;15: 301-12.

165. Conradi S, Ronnevi LO, Vesterberg O. Lead concentration in skeletal muscle in amyotrophic lateral sclerosis patients and control subjects. J Neurol Neurosurg Psychiatry 1978;41: $1001-4$.

166. Conradi S, Ronnevi LO, Nise G, Vesterberg O. Abnormal distribution of lead in amyotrophic lateral sclerosis - reestimation of lead in the cerebrospinal fluid. J Neurol Sci 1980;48: 413-8.

167. Kurlander HM, Patten BM. Metals in spinal cord tissue of patients dying of motor neuron disease. Ann Neurol 1979;6:21-4.

168. Vinceti M, Bergomi M, Vivoli G. Effect of naturally-occurring exposure to selenium through drinking water on mortality from cancer and cardiovascular disease. Epidemiology 1997;8: S35.
169. Cavalleri A, Minoia C, Ceroni M, Poloni M. Lead in cerebrospinal fluid and its relationship to plasma lead in humans. J Appl Toxicol 1984;4:63-5.

170. House AO, Abbott RJ, Davidson DL, Ferguson IT, Lenman JA. Response to penicillamine of lead concentrations in CSF and blood in patients with motor neurone disease. Br Med J 1978;2:1684

171. Pierce-Ruhland R, Patten BM. Muscle metals in motor neuron disease. Ann Neurol 1980;8:193-5.

172. Stober T, Stelte W, Kunze K. Lead concentrations in blood, plasma, erythrocytes, and cerebrospinal fluid in amyotrophic lateral sclerosis. J Neurol Sci 1983;61:21-6.

173. Gupta R. ST. Cholinesterase-inhibiting pesticides: metabolism, toxicity and epidemiology. USA: John Wiley \& Sons, 2011.

174. Finkelstein Y, Taitelman U, Biegon A. CNS involvement in acute organophosphate poisoning: specific pattern of toxicity, clinical correlates and antidotal treatment. Ital J Neurol Sci 1988;9:437-46.

175. Finkelstein Y, Wolff M, Biegon A. Brain acetylcholinesterase after acute parathion poisoning: a comparative quantitative histochemical analysis post mortem. Ann Neurol 1988;24: 252-7.

176. Battershill JM, Edwards PM, Johnson MK. Toxicological assessment of isomeric pesticides: a strategy for testing of chiral organophosphorus (OP) compounds for delayed polyneuropathy in a regulatory setting. Food Chem Toxicol 2004;42: 1279-85.

177. Morahan JM, Yu B, Trent RJ, Pamphlett R. A gene-environment study of the paraoxonase 1 gene and pesticides in amyotrophic lateral sclerosis. Neurotoxicology 2007;28:532-40.

178. Wills AM, Landers JE, Zhang H, Richter RJ, Caraganis AJ, et al. Paraoxonase 1 (PON1) organophosphate hydrolysis is not reduced in ALS. Neurology 2008;70:929-34.

179. Friedman LS, Brautbar N, Barach P, Wolfe AH, Richter ED. Creatine phosphate kinase elevations signaling muscle damage following exposures to anticholinesterases: 2 sentinel patients. Arch Environ Health 2003;58:167-71.

180. Doi H, Kikuchi H, Murai H, Kawano Y, Shigeto H, et al. Motor neuron disorder simulating ALS induced by chronic inhalation of pyrethroid insecticides. Neurology 2006;67:1894-5.

181. Pall HS, Williams AC, Waring R, Elias E. Motoneurone disease as manifestation of pesticide toxicity. Lancet 1987;ii: 685.

182. Steventon GB, Waring RH, Williams AC. Pesticide toxicity and motor neuron disease. J Neurol Neurosurg Psychiatry 1990;53:621-2.

183. Bonvicini F, Marcello N, Mandrioli J, Pietrini V, Vinceti M. Exposure to pesticides and risk of amyotrophic lateral sclerosis: a population-based case-control study. Ann Ist Super Sanita 2010;46:284-7.

184. Furby A, Beauvais K, Kolev I, Rivain JG, Sebille V. Rural environment and risk factors of amyotrophic lateral sclerosis: a case-control study. J Neurol 2010;257:792-8.

185. Weisskopf MG, Morozova N, O'Reilly EJ, McCullough ML, Calle EE, et al. Prospective study of chemical exposures and amyotrophic lateral sclerosis. J Neurol Neurosurg Psychiatry 2009;80:558-61.

186. Chio A, Calvo A, Dossena M, Ghiglione P, Mutani R, et al. ALS in Italian professional soccer players: the risk is still present and could be soccer-specific. Amyotroph Lateral Scler 2009;10:205-9.

187. Qureshi GA, Qureshi AA, Memon SA, Parvez SH. Impact of selenium, iron, copper and zinc in on/off Parkinson's patients on L-dopa therapy. J Neural Transm Suppl 2006;71:229-36. 
188. Govoni V, Granieri E, Fallica E, Casetta I. Amyotrophic lateral sclerosis, rural environment and agricultural work in the Local Health District of Ferrara, Italy, in the years 1964-1998. J Neurol 2005;252:1322-7.

189. Burns CJ, Beard KK, Cartmill JB. Mortality in chemical workers potentially exposed to 2,4-dichlorophenoxyacetic acid (2,4-D) 1945-94: an update. Occup Environ Med 2001;58:24-30.

190. Freedman M. Amyotrophic lateral sclerosis and occupational exposure to 2,4-dichlorophenoxyacetic acid. Occup Environ Med 2001;58:609-10.

191. Gunnarsson LG, Lygner PE, Veiga-Cabo J, de Pedro-Cuesta J. An epidemic-like cluster of motor neuron disease in a Swedish county during the period 1973-1984. Neuroepidemiology 1996;15:142-52.

192. Kalfakis N, Vassilopoulos D, Voumvourakis C, Ndjeveleka M, Papageorgiou C. Amyotrophic lateral sclerosis in southern
Greece: an epidemiologic study. Neuroepidemiology 1991;10: $170-3$.

193. Gunnarsson LG, Lindberg G, Soderfeldt B, Axelson O. Amyotrophic lateral sclerosis in Sweden in relation to occupation. Acta Neurol Scand 1991;83:394-8.

194. Giagheddu M, Puggioni G, Masala C, Biancu F, Pirari G, et al. Epidemiologic study of amyotrophic lateral sclerosis in Sardinia, Italy. Acta Neurol Scand 1983;68:394-404.

195. Holloway SM, Emery AE. The epidemiology of motor neuron disease in Scotland. Muscle Nerve 1982;5:131-3.

196. Rosati G, Pinna L, Granieri E, Aiello I, Tola R, et al. Studies on epidemiological, clinical, and etiological aspects of ALS disease in Sardinia, Southern Italy. Acta Neurol Scand 1977;55:231-44.

197. Saeed M, Siddique N, Hung WY, Usacheva E, Liu E, et al. Paraoxonase cluster polymorphisms are associated with sporadic ALS. Neurology 2006;67:771-6. 